\title{
Structure, optical properties and thermal stability of pulsed sputter deposited high temperature $\mathrm{HfO}_{\mathrm{x}} / \mathrm{Mo} / \mathrm{HfO}_{2}$ solar selective absorbers
}

\author{
N. Selvakumar, Harish C. Barshilia ${ }^{\text {a) }}$, and K. S. Rajam \\ Surface Engineering Division, National Aerospace Laboratories (CSIR), Bangalore-560 017, \\ India
}

A. Biswas

Applied Spectroscopy Division, Bhabha Atomic Research Center, Mumbai-400 085, India

\begin{abstract}
Solar selective coatings of $\mathrm{HfO}_{\mathrm{x}} / \mathrm{Mo} / \mathrm{HfO}_{2}$ were deposited on copper $(\mathrm{Cu})$ and stainless steel (SS) substrates using a magnetron sputtering system. The $\mathrm{HfO}_{\mathrm{x}}$ and $\mathrm{HfO}_{2}$ layers were deposited from the sputtering of $\mathrm{Hf}$ target in $\mathrm{Ar}+\mathrm{O}_{2}$ plasma using an asymmetric bipolar-pulsed direct current generator. Whereas, the Mo layer was deposited from the sputtering of Mo target in the Ar plasma. The optimized $\mathrm{HfO}_{\mathrm{x}} / \mathrm{Mo} / \mathrm{HfO}_{2}$ multilayer absorber on $\mathrm{Cu}$ substrate exhibited high solar absorptance $(\alpha=0.905-0.923)$ and low thermal emittance $(\varepsilon=0.07-0.09)$. Similarly, on SS substrates the optimized coatings exhibited $\alpha$ and $\varepsilon$ in the ranges of $0.902-0.917$ and $0.15-0.17$, respectively. The X-ray diffraction data showed that the $\mathrm{HfO}_{\mathrm{x}} / \mathrm{Mo} / \mathrm{HfO}_{2}$ coating consists of tetragonal and monoclinic phases of $\mathrm{HfO}_{2}$, which was confirmed by micro-Raman spectroscopy data. The bonding structure of the $\mathrm{HfO}_{\mathbf{x}}$ and the $\mathrm{HfO}_{2}$ layers were confirmed using X-ray photoelectron spectroscopy data. The optical constants ( $n$ and $k$ ), measured using spectroscopic ellipsometry, showed that the top $\mathrm{HfO}_{2}$ layer acts as an antireflection coating and the bottom two layers $\left(\mathrm{HfO}_{\mathrm{x}}\right.$ and $\left.\mathrm{Mo}\right)$ are the main absorber layers. The analysis of the spectroscopic
\end{abstract}

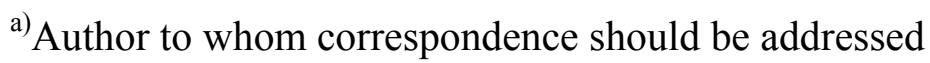
Electronic mail: harish@nal.res.in Fax \#+091-80-25210113
} 
ellipsometric data indicated that the band gap of the $\mathrm{HfO}_{\mathrm{x}}$ and the $\mathrm{HfO}_{2}$ layers were 3.90 and $5.82 \mathrm{eV}$, respectively, indicating non-stoichiometric nature of $\mathrm{HfO}_{\mathrm{x}}$. In order to study the thermal stability of the $\mathrm{HfO}_{\mathrm{x}} / \mathrm{Mo} / \mathrm{HfO}_{2}$ coatings, they were subjected to heat treatment in air and vacuum at different temperatures $\left(\mathrm{T}_{\mathrm{A}}\right)$. The $\mathrm{HfO}_{\mathrm{x}} / \mathrm{Mo} / \mathrm{HfO}_{2}$ coatings deposited on $\mathrm{Cu}$ substrates were thermally stable up to $400^{\circ} \mathrm{C}$ for $2 \mathrm{~h}$ in air. Addition of a thin Mo interlayer $(40 \mathrm{~nm})$ in the $\mathrm{HfO}_{\mathrm{x}} / \mathrm{Mo} / \mathrm{HfO}_{2}$ coating (i.e., $\mathrm{Mo} / \mathrm{HfO}_{\mathrm{x}} / \mathrm{Mo} / \mathrm{HfO}_{2}$ ) deposited on $\mathrm{Cu}$ substrates exhibited high solar selectivity $(\alpha \mathcal{E})$ of $0.872 / 0.09$ even after heat-treatment in air up to $500^{\circ} \mathrm{C}$ for $2 \mathrm{~h}$. At $\mathrm{T}_{\mathrm{A}}=$ $525^{\circ} \mathrm{C}$, the solar selectivity decreased drastically $(\alpha / \mathcal{E}=0.761 / 0.35)$ due to the formation of $\mathrm{MoO}_{2}, \mathrm{MoO}_{3}$ and $\mathrm{HfMo}_{2} \mathrm{O}_{8}$ phases. The $\mathrm{Mo} / \mathrm{HfO}_{\mathrm{x}} / \mathrm{Mo} / \mathrm{HfO}_{2}$ coatings deposited on SS substrates showed no significant changes in $\alpha$ and $\varepsilon$ values after annealing at $500^{\circ} \mathrm{C}$ in air and at $800^{\circ} \mathrm{C}$ in vacuum. These results were confirmed by micro-Raman spectroscopy measurements, which showed the compositional stability of these coatings up to $500^{\circ} \mathrm{C}$ in air and $800^{\circ} \mathrm{C}$ in vacuum. 


\section{Introduction}

Transition metal oxide coatings such as $\mathrm{Cr}_{2} \mathrm{O}_{3}, \mathrm{MoO}_{3}, \mathrm{WO}_{\mathrm{x}}$, etc. have been used for solar selective applications due to their excellent optical properties and good thermal stability. ${ }^{1}$ The optical properties of transition metal based coatings can be tailored by controlling the stoichiometry, which affects the density of free electrons in the $d$ band. ${ }^{1}$ Among transition metal oxides, especially hafnium oxide $\left(\mathrm{HfO}_{2}\right)$ coatings are technologically important because of their good mechanical, chemical and thermal stability as well as relatively high dielectric constant and high refractive index $(n) .^{2}$ The wide band gap $(5.5 \mathrm{eV})$ of $\mathrm{HfO}_{2}$ gives it transparency over a wide spectral range, extending from the ultraviolet to the mid-infrared (IR). ${ }^{3}$ Due to its large band gap and high refractive index, $\mathrm{HfO}_{2}$ is an interesting candidate for optical applications. $\mathrm{HfO}_{2}$ is used as an optical coating for astronomically charged coupled devices ${ }^{4}$, antireflective multilayer coating for night vision devices ${ }^{5}$, high reflectivity mirrors and for IR optical devices. ${ }^{6,7}$

The optical properties of single layer hafnium oxide thin films have been studied extensively. ${ }^{8-11}$ Khoshman and Kordesch reported that amorphous $\mathrm{HfO}_{2}$ films exhibited high transmittivity $(80-97 \%)$ and low reflectivity $(<15 \%)$ in the visible and the near IR regions, respectively. ${ }^{8}$ Park et al. have reported that the optical properties of $\mathrm{HfO}_{2}$ films are directly correlated with the crystal structure of $\mathrm{HfO}_{2} .{ }^{9}$ Al-Kuhaili developed hafnium oxide based heat mirror $\left(\mathrm{HfO}_{2} / \mathrm{Ag} / \mathrm{HfO}_{2}\right)$, which exhibited an average transmittance of $72.4 \%$ in the wavelength range of 700-2000 nm. ${ }^{3}$ He also reported that the $\mathrm{HfO}_{2}$ based heat mirror can be used for energy efficient window applications. To the best of our knowledge, $\mathrm{HfO}_{2}$ based multilayer absorber coatings for high temperature solar thermal applications have not been developed and studied so far. Detailed studies regarding the absorptance and the thermal stability of the $\mathrm{HfO}_{2}$ 
based coatings are lacking. We have investigated the possibility of designing a dielectric/metal/dielectric (D/M/D) multilayer absorber coating of $\mathrm{HfO}_{2}$ and molybdenum.

The $\mathrm{HfO}_{2}$ coatings have been mainly prepared by electron beam evaporation, atomic layer deposition, pulsed laser deposition, chemical vapor deposition and sputtering methods. ${ }^{2,3,8,9,12,13}$ In most of the sputter deposited $\mathrm{HfO}_{2}$ coatings, reactive direct current (DC) and radio frequency $(\mathrm{RF})$ sputtering methods have been used. DC sputtering has serious limitations for the sputtering of oxides and RF sputtering suffers from low growth rates and its complexity. Recently, pulsed sputtering has been developed for the deposition of highly adherent, uniform and dense coatings of dielectric nitrides and oxides with high growth rates. ${ }^{14}$ Asymmetric bipolar-pulsed DC generators have been successfully used for the deposition of insulating films from the reactive sputtering of metal targets.

In the present work, we have designed an $\mathrm{HfO}_{\mathrm{x}} / \mathrm{Mo} / \mathrm{HfO}_{2}$ multilayer absorber coating with high absorptance and low emittance for high temperature solar applications. Asymmetric bipolar-pulsed DC generator was used to develop the $\mathrm{HfO}_{\mathrm{x}} / \mathrm{Mo} / \mathrm{HfO}_{2}$ multilayer absorber coatings on copper $(\mathrm{Cu})$ and stainless steel (SS) substrates. By switching on and off the oxygen flow, alternate layers of hafnium oxide and molybdenum were deposited. The flow rate of oxygen was controlled manually by switching on and off the mass flow controller. In order to achieve the exact composition, each layer was deposited after stabilizing the plasma for five minutes during which a shutter was used in between the substrate and the target. The structural, chemical and optical properties of these coatings have been studied using X-ray diffraction (XRD), X-ray photoelectron spectroscopy (XPS), atomic force microscopy (AFM), microRaman spectroscopy, field emission scanning electron microscopy (FESEM), solar spectrum 
reflectometer and emissometer and phase-modulated spectroscopic ellipsometry. We discuss in detail the thermal stability of these coatings in air and in vacuum.

\section{EXPERIMENTAL DETAILS}

$\mathrm{HfO}_{\mathrm{X}} / \mathrm{Mo} / \mathrm{HfO}_{2}$ coatings were prepared on $\mathrm{Cu}$ substrates (dimension: $35 \mathrm{~mm} \times 35 \mathrm{~mm} \times$ $2 \mathrm{~mm}$ ) using a reactive DC unbalanced magnetron sputtering system. ${ }^{14}$ Before putting the substrates into the vacuum chamber, they were metallographically polished and chemically cleaned. The vacuum chamber was pumped down to a base pressure of $5.0 \times 10^{-4} \mathrm{~Pa}$. High purity Hf $(99.95 \%)$ and Mo $(99.95 \%)$ targets (diameter $=0.075 \mathrm{~m})$ were used for the deposition of the coatings. An asymmetric bipolar-pulsed generator (frequency $=100 \mathrm{kHz}$, pulse width $=2976 \mathrm{ns,}$ positive pulse bias $=+37 \mathrm{~V}$ ) was used to sputter the $\mathrm{Hf}$ target. ${ }^{14}$ The $\mathrm{HfO}_{2}$ layer was prepared from the reactive sputtering of $\mathrm{Hf}$ target in $\mathrm{Ar}+\mathrm{O}_{2}$ plasma at a pressure of $1.0 \times 10^{-1} \mathrm{~Pa}$. For the deposition of the bottom $\mathrm{HfO}_{\mathrm{x}}$ layer, the power density was $9 \mathrm{~W} / \mathrm{cm}^{2}$ and the oxygen flow rate was $6 \mathrm{sccm}$. The Mo metal layer was deposited from the non-reactive sputtering of the metal target in Ar plasma at a pressure of $1.0 \times 10^{-1} \mathrm{~Pa}$. Sputtering was carried out at a power density of $3.4 \mathrm{~W} / \mathrm{cm}^{2}$ for the Mo metal layer. For the top $\mathrm{HfO}_{2}$ layer, the power density was $9 \mathrm{~W} / \mathrm{cm}^{2}$ and the oxygen flow rate was $8 \mathrm{sccm}$. All the coatings were deposited at a substrate temperature of approximately $40-50^{\circ} \mathrm{C}$.

The absorptance $(\alpha)$ and emittance $(\varepsilon)$ of the $\mathrm{HfO}_{\mathrm{x}} / \mathrm{Mo} / \mathrm{HfO}_{2}$ coatings were measured using solar spectrum reflectometer (Model SSR) and emissometer (Model AE) of M/s. Devices and Services. For the solar spectrum reflectometer, the source of the illumination was a tungsten-halogen lamp. The radiation reflected by the sample was measured at an angle of $20^{\circ}$ from the normal, with four filtered detectors (UV, blue, red and infrared). By summing the four outputs in the appropriated proportions, a solar spectrum measurement was achieved. Air mass 
2 was used to calibrate the solar reflectometer. The emissometer was heated to $82^{\circ} \mathrm{C}$, so that the sample to be measured need not be heated. Both the instruments were calibrated using standard samples. This emissometer is a special purpose instrument to measure the emittance of absorber coatings used for flat plate solar thermal collector, wherein the maximum working temperature of the collector is of the order of $80-85^{\circ} \mathrm{C}$. At $82^{\circ} \mathrm{C}$, the spectral range of the thermal radiation emitted from the surface is in the range of 3-30 $\mu \mathrm{m} .{ }^{1}$ The detector in the emissometer consists of a differential thermopile with low and high emittance areas, which ensures near constant response to the emitted radiation in this wavelength range. The accuracies of the measured $\alpha$ values are $\pm 2 \%$ with a drift of $\pm 1 \%+0.003 / \mathrm{h}$ and the emissometer has a repeatability of \pm 0.01 units. The absorptance and the emittance values were measured at four different positions and the values reported herein are the average of four measurements. The ellipsometric data were measured in a spectroscopic phase modulated ellipsometer (Model UVISELTM 460, ISA JOBIN-YVON SPEX) in the wavelength range of 350-1200 $\mathrm{nm}$.

XRD patterns of the coating were recorded in a Rigaku D/max 2200 Ultima X-ray powder diffractometer. The X-ray source was a $\mathrm{Cu} \mathrm{K}_{\alpha}$ radiation $(\lambda=0.15418 \mathrm{~nm})$, which was operated at $40 \mathrm{kV}$ and $30 \mathrm{~mA}$. The bonding structure of the coatings was characterized by XPS using an ESCA 3000 (V.G. Microtech) system with a monochromatic Al K $\alpha$ X-ray beam (energy $=1486.5 \mathrm{eV}$ and power $=150$ watts). The microstructure of the coatings was studied using field-emission scanning electron microscopy (Supra 40VP, Carl Zeiss). Approximately $10 \mathrm{~nm}$ thick gold coating was deposited on $\mathrm{HfO}_{\mathrm{x}} / \mathrm{Mo} / \mathrm{HfO}_{2}$ coatings for FESEM measurements. The surface roughness of the coatings was measured using atomic force microscopy (Surface Imaging Systems). 
In order to test the thermal stability, the $\mathrm{HfO}_{\mathrm{x}} / \mathrm{Mo} / \mathrm{HfO}_{2}$ coatings deposited on copper and stainless steel substrates were heated in air in a resistive tubular furnace at temperatures in the range of $200-525^{\circ} \mathrm{C}$ for $2 \mathrm{~h}$. The hot zone of the furnace was $0.05 \mathrm{~m}$ in diameter and $0.05 \mathrm{~m}$ in length. The accuracy of the set temperature was $\pm 5^{\circ} \mathrm{C}$. Annealing involved increasing the temperature of the samples from room temperature to the desired temperature at a slow heating rate of $5^{\circ} \mathrm{C} / \mathrm{min}$ and maintaining the desired temperature for $2 \mathrm{~h}$. Subsequently, the samples were cooled down at a rate of $5^{\circ} \mathrm{C} / \mathrm{min}$. Changes in the chemical composition of the solar selective coatings as a result of heating were measured using micro-Raman spectroscopy. A DILOR-JOBIN-YVON-SPEX integrated Raman spectrometer (Model Labram) was used for the present experiments. ${ }^{15}$ The spectrometer consisted of a microscope coupled confocally to a $300 \mathrm{~mm}$ focal length spectrograph equipped with two switchable gratings (300 and 1800 grooves $/ \mathrm{mm}$ ). A HeNe $20 \mathrm{~mW}$ laser beam was used as the excitation source. The laser was totally reflected by a notch filter towards the sample under a microscope and the Raman scattering was totally transmitted through the notch filter towards the confocal hole and entrance slit of the spectrometer. The spectrum was recorded in a Peltier cooled charge coupled devices detector. The data were collected with a 20 seconds data point acquisition time in the spectral range of 50-1100 $\mathrm{cm}^{-1}$. The thermal stability of the coatings in vacuum $\left(5.0 \times 10^{-4} \mathrm{~Pa}\right)$ was also studied using micro-Raman spectroscopy. Molybdenum strips were used as heating elements to heat a stainless steel 316 thick plate, on which the test samples were placed. A diffusion pump was used to create the vacuum. The accuracy of the set temperature was \pm $10^{\circ} \mathrm{C}$. A heating rate of $5^{\circ} \mathrm{C} / \mathrm{min}$ and a cooling rate of $5^{\circ} \mathrm{C} / \mathrm{min}$ were used.

\section{RESULTS AND DISCUSSION}

\section{A. Design of $\mathrm{HfO}_{\mathrm{x}} / \mathrm{Mo} / \mathrm{HfO}_{2}$ multilayer absorbers}


A multilayer absorber is a combination of single layers with different optical constants and film thicknesses. When an incident light falls on a multilayer absorber, the light interferes with one or more of the waves that are reflected from the various interfaces in the multilayer coatings. ${ }^{16}$ Generally, light reflected from the interfaces will experience a $180^{\circ}$ phase change when it is reflected from a medium of high refractive index and no phase change will occur, when it is reflected from a medium of low refractive index. The phases and the amplitudes of these waves determine whether the resultant sum of these waves lead to constructive/destructive interference and an increase/decrease in the reflectance of the incident light. ${ }^{16}$

A schematic diagram of the $\mathrm{HfO}_{\mathrm{x}} / \mathrm{Mo} / \mathrm{HfO}_{2}$ multilayer absorber coating deposited on $\mathrm{Cu}$ substrate is shown in Fig. 1. The coating consists of a semitransparent Mo metal layer (layer 2 approximately $31 \mathrm{~nm}$ thick) sandwiched between $\mathrm{HfO}_{2}$ and $\mathrm{HfO}_{\mathrm{x}}$ layers. Molybdenum was used as a metal layer due to its high infrared reflectance and good solar absorptance. ${ }^{17}$ Its low reflectance in the visible region, when compared to that of noble metals resulted in an increased solar absorptance. Furthermore, the high free electron density of molybdenum leads to high IR reflectivity which results in the desired low emittance in the infrared region. ${ }^{17}$ The bottom absorber layer, $\mathrm{HfO}_{\mathrm{x}}$ (layer 1- approximately $26 \mathrm{~nm}$ thick) is designed to have a lower oxygen content than the top $\mathrm{HfO}_{2}$ layer (layer 3 - approximately $67 \mathrm{~nm}$ thick) in order to achieve different refractive indices for both the layers. The oxygen flow rate was varied in order to achieve the different composition (i.e., $6 \mathrm{sccm}$ for $\mathrm{HfO}_{\mathrm{x}}$ and $8 \mathrm{sccm}$ for $\mathrm{HfO}_{2}$ layer). The top $\mathrm{HfO}_{2}$ layer has higher oxygen content and acts as an antireflection coating. This is because stoichiometric $\mathrm{HfO}_{2}$ has a wide band gap (i.e., $5.82 \mathrm{eV}$ ) which gives it transparency over a wide spectral range (from ultraviolet to mid-infrared region). Whereas, the bottom $\mathrm{HfO}_{\mathrm{x}}$ layer exhibits significant absorption in the visible region which was confirmed by the ellipsometry 
data (explained below). The design of $\mathrm{HfO}_{\mathrm{x}} / \mathrm{Mo} / \mathrm{HfO}_{2}$ multilayer absorber is based on the idea that destructive interference (i.e., interference induced absorption) between adjacent layers leads to an increase in the solar absorptance. This was confirmed by the optical constants data and will be discussed later. The optimized $\mathrm{HfO}_{\mathrm{x}} / \mathrm{Mo} / \mathrm{HfO}_{2}$ coating deposited on $\mathrm{Cu}$ substrate exhibited a high absorptance of the order of 0.905-0.923 and a low emittance of 0.07-0.09 at $82{ }^{\circ} \mathrm{C}$.

\section{B. Structural properties}

Hafnium oxide exhibits several polymorphs such as monoclinic $(\mathrm{m}-)$ phase at room temperature and atmospheric pressure and orthorhombic and tetragonal $(t-)$ phases at high pressures and/or high temperatures. ${ }^{18}$ Fig. 2(a) shows the XRD pattern of the $\mathrm{HfO}_{2}$ coating (approximately $1.0 \mu \mathrm{m}$ thick) deposited at an oxygen flow rate of $8 \mathrm{sccm}$. The coating exhibited both tetragonal and monoclinic phases of $\mathrm{HfO}_{2}$. The XRD pattern shows a high intensity peak

centered at $2 \theta=27.9^{\circ}$ which corresponds to the $(\overline{1} 11)$ plane of monoclinic phase of $\mathrm{HfO}_{2}$. The weak and broad peaks centered at 35.54 and $44.6^{\circ}$ correspond to the (200) and (211) planes of $m$ $\mathrm{HfO}_{2}$, respectively. ${ }^{19}$ Similarly, the peaks at $2 \theta=31.6,33.96^{\circ}, 38.36^{\circ}$ and $50.14^{\circ}$ originate from the (111), (002), (102) and (220) planes of $t-\mathrm{HfO}_{2}$, respectively. ${ }^{20}$

Fig. 2(b) shows the XRD pattern of a typical $\mathrm{HfO}_{\mathrm{x}} / \mathrm{Mo} / \mathrm{HfO}_{2}$ (approximately $125 \mathrm{~nm}$ thick) coating deposited on Si substrate. The XRD pattern shows low intensity peaks centered at $2 \theta=38.32^{\circ}$ and $44.60^{\circ}$, which correspond to (102) plane of $t-\mathrm{HfO}_{2}$ and (211) plane of $m-\mathrm{HfO}_{2}$, respectively. The peak marked with "S" originates from the substrate. No peaks pertaining to crystalline Mo were observed in the XRD data. These results clearly indicate that the hafnium oxide present in the multilayer absorber coating exhibited a mixture of monoclinic and tetragonal phases. 


\section{Micro-Raman spectroscopy studies}

Raman spectroscopy technique was used to characterize the $\mathrm{HfO}_{\mathrm{x}} / \mathrm{Mo} / \mathrm{HfO}_{2}$ coatings as the molecular vibration signatures from a Raman spectrum are very sensitive to chemical structure and bonding, rather than just atomic composition. Group theory predicts 36 phonon modes for $m$ - $\mathrm{HfO}_{2}$, in which 18 modes $\left(9 A_{g}+9 B_{g}\right)$ are Raman active and 15 modes $\left(8 A_{u}+7 B_{u}\right)$ are IR active, the remaining three modes being the zero-frequency translational modes. There are three IR active modes $\left(A_{2 u}+2 E_{u}\right)$ and three Raman active modes $\left(A_{1 g}+B_{1 g}+E_{g}\right)$ for $t-\mathrm{HfO}_{2}{ }^{21}$ Fig. 3(a) shows the Raman spectrum of single layer $\mathrm{HfO}_{2}$ coating deposited on $\mathrm{Si}$ substrates at an oxygen flow rate of $8 \mathrm{sccm}$. The spectrum of single layer $\mathrm{HfO}_{2}$ coating shows three broad and diffused Raman bands centered at 316, 396 and $639 \mathrm{~cm}^{-1}$. The band centered at $316 \mathrm{~cm}^{-1}$ is of $A_{g}$ symmetry and the other bands centered at 396 and $639 \mathrm{~cm}^{-1}$ are attributed to $B_{g}$ symmetry of $m$ $\mathrm{HfO}_{2}{ }^{21}$ The peak centered at $521 \mathrm{~cm}^{-1}$ corresponds to silicon substrate. Fig. 3 (b) shows the Raman spectrum of a typical $\mathrm{HfO}_{\mathrm{x}} / \mathrm{Mo} / \mathrm{HfO}_{2}$ coating and the spectrum shows two strong bands centered at 170 and $210 \mathrm{~cm}^{-1}$ and two weak bands centered at 382 and $629 \mathrm{~cm}^{-1}$. The exact position of various Raman bands was determine using deconvolution of the Raman data as shown in inset of Fig. 3. The bands centered at 170 and $382 \mathrm{~cm}^{-1}$ originate from $B_{g}$ symmetry of $m-\mathrm{HfO}_{2}$ and the other bands centered at 201 and $629 \mathrm{~cm}^{-1}$ may be attributed to $E_{g}$ and $A_{l g}$ symmetry, respectively of $t-\mathrm{HfO}_{2}{ }^{21,22}$ It is worth noting that in the observed spectra, the number of Raman active vibrational modes identified is less than the number of the corresponding modes predicted from the group theory analysis for monoclinic $\mathrm{HfO}_{2}$. This is due to the fact that the Raman active vibrations for $\mathrm{HfO}_{2}$ have very close frequencies those cannot be separated in nonpolarized Raman spectra of polycrystalline samples. ${ }^{23}$

\section{X-ray photoelectron spectroscopy}


Fig. 4(a-c) shows the core level XPS spectra of the single layer $\mathrm{HfO}_{\mathrm{x}}(6 \mathrm{sccm}$-top layer $)$ coating. The $\mathrm{Hf} 4 \mathrm{f}$ spectrum (Fig. 4(a)) of the $\mathrm{HfO}_{\mathrm{x}}$ coating showed two peaks centered at 16.8 and $18.5 \mathrm{eV}$, which originate from $\mathrm{Hf}_{4} 4 \mathrm{f}_{7 / 2}$ and $\mathrm{Hf}_{4} 4 \mathrm{f}_{5 / 2}$, respectively of $\mathrm{HfO}_{\mathrm{x}} \cdot{ }^{24}$ Similarly, the $\mathrm{Hf}$ 4d (Fig. 4(b)) spectrum also showed two peaks centered at 213.4 and $224.2 \mathrm{eV}$ corresponding to $\mathrm{Hf} 4 \mathrm{~d}_{5 / 2}$ and $\mathrm{Hf} 4 \mathrm{~d}_{3 / 2}$, respectively of $\mathrm{HfO}_{\mathrm{x}}$. The higher binding energies of the $\mathrm{HfO}_{\mathrm{x}}$ coating suggest that the hafnium oxide coating was O-deficient, which confirms the formation of nonstoichiometric $\mathrm{HfO}_{\mathrm{x}}{ }^{24}$ The $\mathrm{O}$ 1s spectrum (Fig. 4(c)) showed a characteristic peak at a binding energy of $530.4 \mathrm{eV}$, which corresponds to $\mathrm{O}-\mathrm{Hf}$ bonding. ${ }^{24}$

Fig. 4(d-f) shows core level XPS spectra of the $\mathrm{HfO}_{2}(8 \mathrm{sccm}$-bottom layer) coating. The $\mathrm{Hf} 4 \mathrm{f}$ spectrum (Fig. 4(d)) of the $\mathrm{HfO}_{2}$ coating showed two peaks centered at 16.4 and $18.0 \mathrm{eV}$, which originate from $\mathrm{Hf} 4 \mathrm{f}_{7 / 2}$ and $\mathrm{Hf}_{4} \mathrm{f}_{5 / 2}$, respectively of $\mathrm{HfO}_{2}{ }^{24}$ The shift in the binding energy towards the lower side and the doublet separation of $1.6 \mathrm{eV}$ clearly indicates the formation of stoichiometric $\mathrm{HfO}_{2}$. Similarly, the $\mathrm{Hf} 4 \mathrm{~d}$ (Fig. 4(e)) spectrum also showed two peaks centered at 212.9 and $223.6 \mathrm{eV}$ which correspond to $\mathrm{Hf} 4 \mathrm{~d}_{5 / 2}$ and $\mathrm{Hf} 4 \mathrm{~d}_{3 / 2}$, respectively of $\mathrm{HfO}_{2}$. The O 1s spectrum (Fig. 4(f)) showed a characteristic peak at a binding energy of 530.1 $\mathrm{eV}$, which corresponds to oxygen in $\mathrm{HfO}_{2}{ }^{24}$ It has been reported that fully oxidized metal oxide has lower binding energy $\left(\mathrm{HfO}_{2}-530.1 \mathrm{eV}\right)$ than that of oxygen deficient oxide $\left(\mathrm{HfO}_{\mathrm{x}}-530.4\right.$ $\mathrm{eV}) .^{25}$

\section{E. Optical properties}

Fig. 5 shows the experimental $\psi$ (amplitude ratio of parallel and perpendicular components of the reflected waves) and $\Delta$ (relative phase change) spectra obtained by spectroscopic phase modulated ellipsometry over a wavelength range of 350-1200 nm for the $\mathrm{HfO}_{\mathrm{x}} / \mathrm{Mo} / \mathrm{HfO}_{2}$ coating on $\mathrm{Cu}$ substrate. The above experimental spectra were fitted with a three 
layer model. The $\mathrm{HfO}_{\mathrm{x}}$ and the $\mathrm{HfO}_{2}$ layers were modeled using Adachi's model ${ }^{26-28}$ and the middle metallic Mo layer was modeled using Cauchy's formula ${ }^{29}$ for generating refractive indices $(n)$ and extinction coefficients $(k)$ spectra. ${ }^{26-29}$ The fitting details are described elsewhere in our previous work. ${ }^{28-31}$

The theoretically generated spectra were fitted with experimentally measured ellipsometric spectra by varying thickness and parameters of dispersion relation of every layer for extracting the thickness, refractive indices and extinction coefficients of different layers. The fitting parameters for $\mathrm{HfO}_{\mathrm{x}}$ and $\mathrm{HfO}_{2}$ layers are shown in Table I, where $\mathrm{A}_{0 \mathrm{x}}$ is exciton strength parameter, $G_{0}$ is exciton binding energy, $\varepsilon_{\infty}$ is the higher energy component of the dielectric constant, $\mathrm{A}_{0}$ is the modulation amplitude, $\mathrm{E}_{0}$ is the energy gap between bottom of conduction band and top of the valence band and $\Gamma_{0}$ is the broadening energy. ${ }^{28,31}$ Whereas, for the Mo layer, the Cauchy's model provided the following fitting parameters: $\mathrm{A}=4.55, \mathrm{~B}=$ 84.68, $\mathrm{C}=53.85, \mathrm{D}=197253.35, \mathrm{E}=-24.61$ and $\mathrm{F}=13.95 .^{31} \quad$ More details about fitting procedure can be found elsewhere. ${ }^{28,30}$ In brief, the measured ellipsometric spectra were fitted by minimizing the squared difference $\left(\chi^{2}\right)$ between the measured and calculated values of the ellipsometric parameters. Maximum number of iteration allowed was 100 and criterion for convergence used was $\delta \chi^{2}=0.000001$. In Fig. 5, the best fitted theoretical spectra are shown with the experimental spectra. The thicknesses of the three layers calculated from the fitting are also shown in the inset of Fig. 5. These values are in agreement with values calculated from the cross-sectional FESEM micrograph. Figure 6(a) shows the fractured cross-sectional FESEM micrograph of the $\mathrm{HfO}_{\mathrm{x}} / \mathrm{Mo} / \mathrm{HfO}_{2}$ coating deposited on Si substrate. The corresponding threedimensional atomic force microscopy image is shown in Fig. 6 (b). The average root mean 
square roughness of the $\mathrm{HfO}_{\mathrm{x}} / \mathrm{Mo} / \mathrm{HfO}_{2}$ coating deposited on Si substrate was approximately 2.0 nm.

The refractive indices and the extinction coefficients of the $\mathrm{HfO}_{x}, \mathrm{HfO}_{2}$ (layers 1 and 3) and Mo metal layer (layer 2) in the absorber coating are shown in Fig. 7, which are in good agreement with the values reported by other workers. ${ }^{3,8}$ The $n$ and $k$ values of bottom $\mathrm{HfO}_{\mathrm{x}}$ layer (layer 1; Fig. 7(a)) decreased monotonically with increasing wavelength. This shows that the bottom $\mathrm{HfO}_{\mathrm{x}}$ layer exhibits an intermediate character, i.e., a transition between the dielectric and the metallic behavior. Whereas, the $n$ value of the top $\mathrm{HfO}_{2}$ layer (layer 3), shown in Fig. 7(b), was lower than that of the metallic Mo layer (Fig. 7(c)) and the bottom $\mathrm{HfO}_{\mathrm{x}}$ layer (Fig. 7(a)). The $k$ values for the top $\mathrm{HfO}_{2}$ layer were almost zero $(0.001-0.005)$ in the visible and near-IR regions, indicating its dielectric behavior. These data indicate that the top $\mathrm{HfO}_{2}$ layer mainly acts as an antireflection coating. Fig. 7(c) shows the $n$ and $k$ values of Mo metal layer (layer 2). The $n$ and $k$ values of Mo metal layer increased with increasing wavelength, which confirms the metallic behavior of molybdenum.

In thin films, the absorption takes place mainly due to two mechanisms: i) interference induced absorption ii) intrinsic absorption. The interference induced absorption depends on the refractive index of the coating, whereas the intrinsic absorption depends on the extinction coefficient of the coating. In $\mathrm{HfO}_{\mathrm{x}} / \mathrm{Mo} / \mathrm{HfO}_{2}$ coating, the $n$ and $k$ values are high for the Mo metal layer and the absorption in the Mo metal layer is mainly due to a combination of interference effect and intrinsic absorption. Whereas, for the bottom $\mathrm{HfO}_{\mathrm{x}}$ layer the $n$ is high and the $k$ is low in the wavelength range of 350-1200 nm. Therefore, for the bottom $\mathrm{HfO}_{\mathrm{x}}$ layer the absorption depends mainly on interference mechanism than intrinsic absorption. These results 
clearly showed that the interference induced absorption plays a major role in the absorption of the multilayer absorber coating.

From the $k$ values, we calculated the absorption coefficients $(\beta)$ for all the three layers, which are shown in Fig. 8. The $\beta$ values were calculated from:

$$
\beta=4 \pi k / \lambda \text {. }
$$

For the top $\mathrm{HfO}_{2}$ layer (Fig. 8(a)), the $\beta$ values were low in the visible (e.g., $1.2 \times 10^{3} \mathrm{~cm}^{-1}$ at 400 $\mathrm{nm}$ ) and near-IR regions (e.g., $1.0 \times 10^{2} \mathrm{~cm}^{-1}$ at $1200 \mathrm{~nm}$ ) when compared to the bottom $\mathrm{HfO}_{\mathrm{x}}$ layer (Fig. 8(b)). For the bottom $\mathrm{HfO}_{\mathrm{x}}$ layer (Fig. 8(b)), the $\beta$ values were high in the visible region (e.g., $6.4 \times 10^{4} \mathrm{~cm}^{-1}$ at $\left.400 \mathrm{~nm}\right)$ and relatively low in the near-IR region $\left(4.8 \times 10^{3} \mathrm{~cm}^{-1}\right.$ at $1200 \mathrm{~nm}$ ), indicating its high absorption in the visible region. Whereas, for the Mo layer, the $\beta$ values were high in both visible $\left(3.0 \times 10^{5} \mathrm{~cm}^{-1}\right.$ at $\left.400 \mathrm{~nm}\right)$ and near-IR regions $\left(1.8 \times 10^{5} \mathrm{~cm}^{-1}\right.$ at $1200 \mathrm{~nm}$ ) when compared to the $\mathrm{HfO}_{\mathrm{x}}$ and $\mathrm{HfO}_{2}$ layers. These results indicate that the main contribution to absorption in the $\mathrm{HfO}_{\mathrm{x}} / \mathrm{Mo} / \mathrm{HfO}_{2}$ multilayer absorber coating is due to the semitransparent Mo metal layer and the bottom $\mathrm{HfO}_{\mathrm{x}}$ layer.

\section{F. Thermal stability in air}

In order to study the thermal stability of the $\mathrm{HfO}_{\mathrm{x}} / \mathrm{Mo} / \mathrm{HfO}_{2}$ multilayer absorbers, the coatings were heat-treated in air at different temperatures for $2 \mathrm{~h}$. The absorptance and the emittance values of the heat-treated $\mathrm{HfO}_{x} / \mathrm{Mo} / \mathrm{HfO}_{2}$ multilayer absorber are listed in Table II. It is clear from the Table II that for $\mathrm{HfO}_{\mathrm{x}} / \mathrm{Mo} / \mathrm{HfO}_{2}$ coatings, the absorptance and the emittance values did not change significantly even after heat-treatment at $400^{\circ} \mathrm{C}$ for $2 \mathrm{~h}$. At $\mathrm{T}_{\mathrm{A}}=425^{\circ} \mathrm{C}$, the absorptance value decreased $(\Delta \alpha=-0.111)$ and the emittance value increased $(\Delta \varepsilon=+0.05)$ significantly. This is because at temperatures greater than $350^{\circ} \mathrm{C}$, copper from the substrate starts diffusing into the coating and its subsequent oxide formation results in optical degradation 
in the visible range and decrease of solar absorptance. ${ }^{31}$ Therefore, the $\mathrm{HfO}_{\mathrm{x}} / \mathrm{Mo} / \mathrm{HfO}_{2}$ coating on $\mathrm{Cu}$ substrate is thermally stable in air up to $400^{\circ} \mathrm{C}$ with a solar selectivity of $0.893 / 0.07$.

In order to avoid the diffusion of copper into the coating, approximately $40 \mathrm{~nm}$ thick Mo interlayer was deposited on copper substrate. The addition of Mo interlayer in the multilayer absorber coating has no significant effect in the absorptance and the emittance values. It has been reported that the molybdenum acts as a diffusion barrier for copper up to $600^{\circ} \mathrm{C} .{ }^{32}$ The absorptance and the emittance values of the heat-treated $\mathrm{Mo} / \mathrm{HfO}_{\mathrm{x}} / \mathrm{Mo} / \mathrm{HfO}_{2}$ multilayer absorber are listed in Table III. It is clearly evident from the table that the Mo interlayer acts as a diffusion barrier for copper which resulted in increase in the thermal stability of the coating up to $500^{\circ} \mathrm{C}$. At $\mathrm{T}_{\mathrm{A}}>500^{\circ} \mathrm{C}$, the absorptance value decreased $(\Delta \alpha=-0.161)$ and the emittance value increased drastically $(\Delta \varepsilon=+0.26)$. This degradation was due to the oxidation of Mo present in the coating and also due to the formation of a new phase (i.e., $\mathrm{HfMo}_{2} \mathrm{O}_{8}$ ) which was formed by the reaction between $\mathrm{MoO}_{3} / \mathrm{MoO}_{2}$ and $\mathrm{HfO}_{2}{ }^{33}$ This was confirmed using Raman spectroscopy and will be discussed later.

The $\mathrm{Mo} / \mathrm{HfO}_{\mathrm{x}} / \mathrm{Mo} / \mathrm{HfO}_{2}$ multilayer absorber coating deposited on $\mathrm{Cu}$ substrates delaminated completely at temperatures greater than $525^{\circ} \mathrm{C}$ in air. Therefore, in order to test the structural stability of the multilayer absorber at higher temperatures, the coatings were deposited on SS substrates with Mo interlayer and were heat-treated in air for $2 \mathrm{~h}$ at different temperatures in the range of $400-525^{\circ} \mathrm{C}$. The absorptance and the emittance values of the heat-treated coatings are shown in Table IV. At $\mathrm{T}_{\mathrm{A}}=525^{\circ} \mathrm{C}$, the absorptance value decreased drastically $(\Delta \alpha=-$ $0.142)$ and the emittance value decreased slightly $(\Delta \varepsilon=-0.03)$. The coatings deposited on SS substrates were also degraded completely at $525^{\circ} \mathrm{C}$, the reason for which has been explained earlier. 
The changes in the chemical composition of $\mathrm{Mo} / \mathrm{HfO}_{\mathrm{x}} / \mathrm{Mo} / \mathrm{HfO}_{2}$ coating at higher operating temperatures were studied using micro-Raman spectroscopy. The composite Raman spectra of the as-deposited and multilayer absorbers deposited on $\mathrm{Cu}$ substrates heat-treated up to $525^{\circ} \mathrm{C}$ are shown in Fig. 9. The shape of Raman spectra did not change significantly even after heating the sample up to a temperature of $400^{\circ} \mathrm{C}$, indicating the stable composition/microstructure of the multilayer coatings. At $\mathrm{T}_{\mathrm{A}}=500{ }^{\circ} \mathrm{C}$, six new bands centered at 193, 260, 322, 442, 536 and $728 \mathrm{~cm}^{-1}$ were observed (see inset in Fig. 9). The bands centered at 260 and $322 \mathrm{~cm}^{-1}$ correspond to $A_{g}$ symmetry and band centered at $536 \mathrm{~cm}^{-1}$ corresponds to $B_{g}$ symmetry of $m-\mathrm{HfO}_{2} \cdot{ }^{23}$ Whereas, bands centered at 442 and $728 \mathrm{~cm}^{-1}$ is attributed to vibrations of $m-\mathrm{MoO}_{2} \cdot{ }^{34}$ The oxidation of Mo at $500^{\circ} \mathrm{C}$ resulted in slight decrease in the solar absorptance $\left(\Delta \alpha=-0.038\right.$, see Table III). At $\mathrm{T}_{\mathrm{A}}=525^{\circ} \mathrm{C}$, two new bands centered at 87 and $878 \mathrm{~cm}^{-1}$ were observed, which are attributed to the formation of $\mathrm{HfMo}_{2} \mathrm{O}_{8}$ due to the reaction between $\mathrm{HfO}_{2}$ and $\mathrm{MoO}_{2} / \mathrm{MoO}_{3}{ }^{33}$ The compound $\mathrm{HfMo}_{2} \mathrm{O}_{8}$ can form very easily from the above reaction as the standard Gibb's free energies of formation of $\mathrm{HfMo}_{2} \mathrm{O}_{8}$ from $\mathrm{HfO}_{2}+\mathrm{MoO}_{3}$ and $\mathrm{HfO}_{2}+\mathrm{MoO}_{2}$ are reported to be -1837.89 and $-1877.30 \mathrm{~kJ} / \mathrm{mol}$, respectively. ${ }^{35,36}$ The formation of this new phase resulted in degradation of the multilayer absorber coating. At $\mathrm{T}_{\mathrm{A}}=525^{\circ} \mathrm{C}$, the absorptance decreased $((\Delta \alpha=-0.161)$ and the emittance increased drastically $(\Delta \varepsilon=+0.26$, see Table III).

The Raman spectra of as-deposited $\mathrm{Mo} / \mathrm{HfO}_{\mathrm{x}} / \mathrm{Mo} / \mathrm{HfO}_{2}$ multilayer absorbers deposited on SS substrates and coatings heat-treated up to $525^{\circ} \mathrm{C}$ in air are shown in Fig. 10. The spectrum of as-deposited coating (Fig. 10 (a)) shows four broad bands centered at 95, 152, 284 and $563 \mathrm{~cm}^{-1}$ correspond to $A_{g}$ symmetry of $m-\mathrm{HfO}_{2}$. The deconvoluted Raman spectrum of as-deposited coating is shown in the inset. At $\mathrm{T}_{\mathrm{A}}=500^{\circ} \mathrm{C}$ (Fig. $10(\mathrm{~b})$ ), bands centered at 452,719 and 819 $\mathrm{cm}^{-1}$ were observed which originate due to vibrations of $m-\mathrm{MoO}_{2}$ and $m-\mathrm{MoO}_{3} \cdot{ }^{34,37}$ Whereas, 
the bands centered at 139, 179, 242 and $631 \mathrm{~cm}^{-1}$ correspond to $B_{g}$ symmetry of $\mathrm{HfO}_{2}$. At $\mathrm{T}_{\mathrm{A}}=$ $525^{\circ} \mathrm{C}$ (Fig. 10 (c)), three characteristic Raman peaks of molybdenum oxide were observed. These Raman bands are assigned to the terminal oxygen $(\mathrm{Mo}=\mathrm{O})$ stretching mode at $992 \mathrm{~cm}^{-1}$, the triply connected bridge-oxygen $\left(\mathrm{Mo}_{3}-\mathrm{O}\right)$ stretching mode at $661 \mathrm{~cm}^{-1}$, and the doubly connected bridge-oxygen $\left(\mathrm{Mo}_{2}-\mathrm{O}\right)$ stretching mode at $815 \mathrm{~cm}^{-1} \cdot 37$ For a comparison, the Raman spectrum of $\mathrm{MoO}_{3}$ (heat-treated $\mathrm{Mo}$ in air at $500^{\circ} \mathrm{C}$ for $2 \mathrm{~h}$ ) is shown in the inset. The formation of $\mathrm{HfMo}_{2} \mathrm{O}_{8}$ is clearly evident from the peaks centered at 770 and $942 \mathrm{~cm}^{-1}$.

These results indicated that the fine Mo crystallites in the $\mathrm{Mo} / \mathrm{HfO}_{\mathrm{x}} / \mathrm{Mo} / \mathrm{HfO}_{2}$ coating oxidized in air at $500^{\circ} \mathrm{C}$ and the Mo metal content, responsible for the intrinsic optical absorption, decreases, resulting in a decrease in the solar absorptance. In addition, at $\mathrm{T}_{\mathrm{A}} \geq 500$ ${ }^{\circ} \mathrm{C}$ the formation of a new phase due to the reaction of $\mathrm{MoO}_{3} / \mathrm{MoO}_{2}$ with $\mathrm{HfO}_{2}$, i.e., $\mathrm{HfMo}_{2} \mathrm{O}_{8}$ (as evident from the Raman data) resulted in a decrease in the absorptance. ${ }^{33}$ It is believed that the formation of $\mathrm{HfMo}_{2} \mathrm{O}_{8}$ leads to crack formation, delamination, and subsequent oxidation of the coating because of the large difference in the thermal expansion coefficients of $\mathrm{HfMo}_{2} \mathrm{O}_{8}$ ($\left.4.0 \times 10^{-6} /{ }^{\circ} \mathrm{C}\right), \mathrm{HfO}_{2}\left(3.8 \times 10^{-6} /{ }^{\circ} \mathrm{C}\right)$ and $\mathrm{Cu}$ substrate $\left(16.5 \times 10^{-6} /{ }^{\circ} \mathrm{C}\right) .{ }^{31,33}$

\section{G. Thermal stability in vacuum}

In addition to the oxide formation, heating of the multilayer absorber in air also leads to phase transformation. Both the phase transformation and the presence of oxides affect the nature of the Raman spectra. In order to study whether the coatings were stable at higher annealing temperatures, they were heated under high vacuum $\left(5.0 \times 10^{-4} \mathrm{~Pa}\right)$ for $2 \mathrm{~h}$ at different temperatures. The absorptance and the emittance values of the $\mathrm{Mo} / \mathrm{HfO}_{\mathrm{x}} / \mathrm{Mo} / \mathrm{HfO}_{2}$ coatings deposited on $\mathrm{Cu}$ and SS substrates after heat-treatment are listed in Table V and VI, respectively. For coatings deposited on $\mathrm{Cu}$ substrates, even after heat-treatment up to $800^{\circ} \mathrm{C}$, there was no 
measurable change in the emittance but a slight decrease $(\Delta \alpha=-0.024)$ in the absorptance was observed as a result of vacuum annealing. Whereas, for coatings deposited on SS substrates, the absorptance decreased $\left(\Delta \alpha=-0.033\right.$, at $\left.\mathrm{T}_{\mathrm{A}}=800{ }^{\circ} \mathrm{C}\right)$ and no significant change in the emittance $(\Delta \varepsilon=+0.01)$ was observed. Fig. 11 shows the deconvoluted Raman spectra of as-deposited and vacuum annealed $\mathrm{Mo} / \mathrm{HfO}_{\mathrm{x}} / \mathrm{Mo} / \mathrm{HfO}_{2}$ coatings deposited on $\mathrm{Cu}$ substrates. It is quite clear from the spectra that annealing of the $\mathrm{Mo} / \mathrm{HfO}_{\mathrm{x}} / \mathrm{Mo} / \mathrm{HfO}_{2}$ coatings in vacuum up to $800{ }^{\circ} \mathrm{C}$ did not change the nature of the Raman spectra. These results are in agreement with the absorptance and emittance data.

\section{Conclusions}

The $\mathrm{HfO}_{\mathrm{x}} / \mathrm{Mo} / \mathrm{HfO}_{2}$ multilayer absorber coatings deposited on $\mathrm{Cu}$ substrates exhibited high solar absorptance $(\alpha=0.905-0.923)$ and low thermal emittance $(\varepsilon=0.07-0.09)$. The XRD data indicated the presence of $m$ - and $t-\mathrm{HfO}_{2}$ in the $\mathrm{HfO}_{\mathrm{x}} / \mathrm{Mo} / \mathrm{HfO}_{2}$ multilayer absorber coating. The optical constants of $\mathrm{HfO}_{\mathrm{x}}, \mathrm{Mo}$ and $\mathrm{HfO}_{2}$ layers measured from the ellipsometric data clearly showed that the Mo and the $\mathrm{HfO}_{\mathrm{x}}$ layers are the main absorber layers and the top $\mathrm{HfO}_{2}$ layer acts as an antireflection coating. The $\mathrm{HfO}_{\mathrm{x}} / \mathrm{Mo} / \mathrm{HfO}_{2}$ coatings deposited on $\mathrm{Cu}$ substrates were thermally stable up to $400^{\circ} \mathrm{C}$ for $2 \mathrm{~h}$ in air. Above $400^{\circ} \mathrm{C}$, the absorptance value decreased drastically due to diffusion of $\mathrm{Cu}$ from the substrate and its subsequent oxide formation. Whereas, $\mathrm{Mo} / \mathrm{HfO}_{\mathrm{x}} / \mathrm{Mo} / \mathrm{HfO}_{2}$ multilayer absorber coatings on $\mathrm{Cu}$ substrates were stable up to $500^{\circ} \mathrm{C}$ in air $(2 \mathrm{~h})$ with a solar selectivity of $0.872 / 0.09$. This result clearly showed that the Mo $(40 \mathrm{~nm})$ layer acts as a diffusion barrier for $\mathrm{Cu}$. The $\mathrm{Mo} / \mathrm{HfO}_{\mathrm{x}} / \mathrm{Mo} / \mathrm{HfO}_{2}$ coatings deposited on SS substrates were also stable up to $500^{\circ} \mathrm{C}$ with a solar selectivity of $0.874 / 0.15$. The oxidation of the $\mathrm{Mo}$ at $500^{\circ} \mathrm{C}$ and the formation of $\mathrm{MoO}_{3} / \mathrm{MoO}_{2}$ and $\mathrm{HfMo}_{2} \mathrm{O}_{8}$ phases at $525^{\circ} \mathrm{C}$ resulted in degradation of the multilayer absorber coatings. The micro-Raman spectroscopy data confirmed 
the formation of $\mathrm{MoO}_{2} / \mathrm{MoO}_{3}$ and $\mathrm{HfMo}_{2} \mathrm{O}_{8}$ at temperatures $\geq 500^{\circ} \mathrm{C}$ for coatings deposited on both $\mathrm{Cu}$ and SS substrates. Vacuum annealing studies of $\mathrm{Mo} / \mathrm{HfO}_{\mathrm{x}} / \mathrm{Mo} / \mathrm{HfO}_{2}$ coatings showed marginal changes in the absorptance and emittance values up to $800^{\circ} \mathrm{C}$. The compositional stability of the coatings in air (up to $500^{\circ} \mathrm{C}$ ) and vacuum (up to $800^{\circ} \mathrm{C}$ ) was confirmed using Raman spectroscopy.

\section{Acknowledgements}

The authors thank the Director, NAL (CSIR) for giving permission to publish these results. Financial support from Ministry of New and Renewable Energy, New Delhi is acknowledged. 
TABLE I: Optical parameters of $\mathrm{HfO}_{2}$ and $\mathrm{HfO}_{x}$ layers extracted using spectroscopic ellipsometry by employing Adachi model.

\begin{tabular}{|c|l|l|}
\hline $\begin{array}{c}\text { Fitting } \\
\text { Parameters }\end{array}$ & $\mathrm{HfO}_{2}$ & $\mathrm{HfO}_{\mathrm{x}}$ \\
\hline$\varepsilon(\infty)$ & 0.69 & 1.28 \\
\hline $\mathrm{E}_{0}$ & $5.82 \mathrm{eV}$ & $3.90 \mathrm{eV}$ \\
\hline$\Gamma_{0}$ & $0.068 \mathrm{eV}$ & $1.61 \mathrm{eV}$ \\
\hline $\mathrm{A}_{0}$ & $101.05 \mathrm{eV}^{1.5}$ & $63.47 \mathrm{eV}^{1.5}$ \\
\hline $\mathrm{A}_{0 \mathrm{x}}$ & $0.0073 \mathrm{eV}$ & $0.0073 \mathrm{eV}$ \\
\hline $\mathrm{G}_{0}$ & $0.064 \mathrm{eV}$ & $0.064 \mathrm{eV}$ \\
\hline
\end{tabular}


Table II. Effect of $2 \mathrm{~h}$ annealing (in air) on the absorptance and emittance values of $\mathrm{HfO}_{\mathrm{x}} / \mathrm{Mo} / \mathrm{HfO}_{2}$ coatings deposited on copper substrates.

\begin{tabular}{|c|c|c|c|c|c|c|}
\hline $\begin{array}{c}\text { Annealing } \\
\text { Temperature } \\
\left({ }^{\circ} \mathrm{C}\right)\end{array}$ & \multicolumn{3}{|c|}{$\alpha$} & \multicolumn{3}{c|}{$\in$} \\
\cline { 2 - 7 } & As-deposited & Annealed & $\Delta \alpha$ & As-deposited & Annealed & $\Delta \in$ \\
\hline 400 & 0.917 & 0.893 & -0.024 & 0.07 & 0.07 & 0.00 \\
\hline 425 & 0.913 & 0.802 & -0.111 & 0.07 & 0.12 & +0.05 \\
\hline 500 & 0.916 & 0.611 & -0.305 & 0.06 & 0.28 & +0.22 \\
\hline
\end{tabular}


Table III. Effect of $2 \mathrm{~h}$ annealing (in air) on the absorptance and emittance values of $\mathrm{Mo} / \mathrm{HfO}_{2} / \mathrm{Mo} / \mathrm{HfO}_{2}$ coatings deposited on copper substrates.

\begin{tabular}{|c|c|c|c|c|c|c|}
\hline \multirow{2}{*}{$\begin{array}{c}\text { Annealing } \\
\text { Temperature } \\
\left({ }^{\circ} \mathrm{C}\right)\end{array}$} & \multicolumn{3}{|c|}{$\alpha$} & \multicolumn{3}{c|}{$\in$} \\
\cline { 2 - 7 } & As-deposited & Annealed & $\Delta \alpha$ & As-deposited & Annealed & $\Delta \in$ \\
\hline 200 & 0.918 & 0.917 & -0.001 & 0.08 & 0.08 & 0.00 \\
\hline 300 & 0.922 & 0.914 & -0.008 & 0.09 & 0.10 & +0.01 \\
\hline 400 & 0.922 & 0.898 & -0.024 & 0.07 & 0.08 & +0.01 \\
\hline 500 & 0.910 & 0.872 & -0.038 & 0.09 & 0.09 & 0.00 \\
\hline 525 & 0.922 & 0.761 & -0.161 & 0.09 & 0.35 & +0.26 \\
\hline
\end{tabular}


Table IV. Effect of $2 \mathrm{~h}$ annealing (in air) on the absorptance and emittance values of $\mathrm{Mo} / \mathrm{HfO}_{2} / \mathrm{Mo} / \mathrm{HfO}_{2}$ coatings deposited on SS substrates.

\begin{tabular}{|c|c|c|c|c|c|c|}
\hline \multirow{2}{*}{$\begin{array}{c}\text { Annealing } \\
\text { Temperature } \\
\left({ }^{\circ} \mathrm{C}\right)\end{array}$} & \multicolumn{3}{|c|}{$\alpha$} & \multicolumn{3}{c|}{$\in$} \\
\cline { 2 - 7 } & As-deposited & Annealed & $\Delta \alpha$ & As-deposited & Annealed & $\Delta \in$ \\
\hline 400 & 0.908 & 0.904 & -0.004 & 0.17 & 0.17 & 0.00 \\
\hline 500 & 0.902 & 0.874 & -0.028 & 0.17 & 0.15 & -0.02 \\
\hline 525 & 0.914 & 0.772 & -0.142 & 0.17 & 0.14 & -0.03 \\
\hline
\end{tabular}


Table V. Effect of $2 \mathrm{~h}$ annealing (in vacuum) on the absorptance and emittance values of $\mathrm{Mo} / \mathrm{HfO}_{2} / \mathrm{Mo} / \mathrm{HfO}_{2}$ coatings deposited on copper substrates.

\begin{tabular}{|c|c|c|c|c|c|c|}
\hline \multirow{2}{*}{$\begin{array}{c}\text { Annealing } \\
\text { Temperature } \\
\left({ }^{\circ} \mathrm{C}\right)\end{array}$} & \multicolumn{3}{|c|}{$\alpha$} & \multicolumn{3}{c|}{$\in$} \\
\cline { 2 - 7 } & As-deposited & Annealed & $\Delta \alpha$ & As-deposited & Annealed & $\Delta \in$ \\
\hline 500 & 0.923 & 0.923 & 0.000 & 0.09 & 0.08 & -0.01 \\
\hline 600 & 0.919 & 0.919 & 0.000 & 0.08 & 0.08 & 0.00 \\
\hline 700 & 0.919 & 0.899 & -0.020 & 0.08 & 0.07 & -0.01 \\
\hline 800 & 0.917 & 0.893 & -0.024 & 0.08 & 0.08 & 0.00 \\
\hline
\end{tabular}


Table VI. Effect of $2 \mathrm{~h}$ annealing (in vacuum) on the absorptance and emittance values of $\mathrm{Mo} / \mathrm{HfO}_{2} / \mathrm{Mo} / \mathrm{HfO}_{2}$ coatings deposited on SS substrates.

\begin{tabular}{|c|c|c|c|c|c|c|}
\hline \multirow{2}{*}{$\begin{array}{c}\text { Annealing } \\
\text { Temperature } \\
\left({ }^{\circ} \mathrm{C}\right)\end{array}$} & \multicolumn{3}{|c|}{$\alpha$} & \multicolumn{3}{c|}{$\in$} \\
\cline { 2 - 7 } & As-deposited & Annealed & $\Delta \alpha$ & As-deposited & Annealed & $\Delta \in$ \\
\hline 600 & 0.917 & 0.894 & -0.023 & 0.17 & 0.12 & -0.05 \\
\hline 700 & 0.911 & 0.890 & -0.021 & 0.16 & 0.13 & -0.03 \\
\hline 800 & 0.912 & 0.879 & -0.033 & 0.16 & 0.17 & +0.01 \\
\hline
\end{tabular}




\section{Figure Captions}

FIG. 1. Schematic diagram of the $\mathrm{HfO}_{\mathrm{x}} / \mathrm{Mo} / \mathrm{HfO}_{2}$ multilayer absorber coating deposited on copper substrate.

FIG. 2. XRD patterns of (a) single layer $\mathrm{HfO}_{2}$ coating deposited on $\mathrm{Si}$ substrate at an $\mathrm{O}_{2}$ flow rate of $8 \mathrm{sccm}$ (b) a typical $\mathrm{HfO}_{\mathrm{x}} / \mathrm{Mo} / \mathrm{HfO}_{2}$ multilayer absorber coating deposited on $\mathrm{Si}$ substrate.

FIG. 3. Raman spectra of: (a) single layer $\mathrm{HfO}_{2}$ coating deposited on $\mathrm{Si}$ substrate at an oxygen flow rate of $8 \mathrm{sccm}$ and (b) $\mathrm{HfO}_{\mathrm{x}} / \mathrm{Mo} / \mathrm{HfO}_{2}$ multilayer absorber coating deposited on $\mathrm{Cu}$ substrate. The inset shows the deconvoluted Raman spectrum of $\mathrm{HfO}_{\mathrm{x}} / \mathrm{Mo} / \mathrm{HfO}_{2}$ multilayer absorber coating.

FIG. 4. Core level XPS spectra of: (a) $\mathrm{Hf} 4 f$, (b) $\mathrm{Hf} 4 d$ and (c) $\mathrm{O} 1 s$ for the as-deposited $\mathrm{HfO}_{\mathrm{x}}$ coating deposited at an $\mathrm{O}_{2}$ flow rate of $6 \mathrm{sccm}$ (layer 1). Also shown is the core level XPS spectra of: (d) $\mathrm{Hf} 4 f$, (e) $\mathrm{Hf} 4 d$ and (f) $\mathrm{O} 1 s$ for the $\mathrm{HfO}_{2}$ coating deposited at an $\mathrm{O}_{2}$ flow rate of $8 \operatorname{sccm}$ (layer 3).

FIG. 5. Variations of experimentally determined $\psi$ and $\Delta$ values with wavelength along with best-fit theoretical curves for the optimized $\mathrm{HfO}_{\mathrm{x}} / \mathrm{Mo} / \mathrm{HfO}_{2}$ coating deposited on $\mathrm{Cu}$ substrate. The dotted lines represent theoretical fits to the experimental data.

FIG. 6. (a) FESEM cross-sectional micrograph of $\mathrm{HfO}_{\mathrm{x}} / \mathrm{Mo} / \mathrm{HfO}_{2}$ coating deposited on $\mathrm{Si}$ substrate and (b) three-dimensional AFM image of $\mathrm{HfO}_{\mathrm{x}} / \mathrm{Mo} / \mathrm{HfO}_{2}$ coating deposited on $\mathrm{Si}$ substrate.

FIG. 7. Variations of experimentally determined $n$ and $k$ values for (a) $\mathrm{HfO}_{\mathrm{x}}$ (layer 1), (b) $\mathrm{HfO}_{2}$ (layer 3) and (c) Mo (layer 2).

FIG. 8. Variations of absorption coefficients for (a) $\mathrm{HfO}_{2}$ layer, (b) $\mathrm{HfO}_{\mathrm{x}}$ layer and (c) Mo layer. 
FIG. 9. Composite Raman spectra of as-deposited $\mathrm{Mo} / \mathrm{HfO}_{\mathrm{x}} / \mathrm{Mo} / \mathrm{HfO}_{2}$ coating on $\mathrm{Cu}$ substrate and coatings heat-treated up to $525^{\circ} \mathrm{C}$ for $2 \mathrm{~h}$ in air. Also shown in the inset is the deconvoluted Raman spectrum of coating heat-treated at $500^{\circ} \mathrm{C}$.

FIG. 10. Composite Raman spectra of as-deposited $\mathrm{Mo} / \mathrm{HfO}_{\mathrm{x}} / \mathrm{Mo} / \mathrm{HfO}_{2}$ coating on $\mathrm{SS}$ substrate and coatings heat-treated up to $525^{\circ} \mathrm{C}$ for $2 \mathrm{~h}$ in air. Also shown in the insets are the deconvoluted Raman spectrum of as-deposited coating and Raman spectrum of $\mathrm{MoO}_{3}$.

FIG. 11. Deconvoluted Raman spectra of: (a) as-deposited $\mathrm{Mo} / \mathrm{HfO}_{\mathrm{x}} / \mathrm{Mo} / \mathrm{HfO}_{2}$ coating on $\mathrm{Cu}$ substrate and coatings vacuum annealed at (b) $600^{\circ} \mathrm{C}$, (c) $700^{\circ} \mathrm{C}$ and (d) $800^{\circ} \mathrm{C}$ for $2 \mathrm{~h}$. 


\section{References}

${ }^{1}$ Solar Energy Conversion: Solid State Physics Aspects: Topics in Applied Physics, edited by B.O. Seraphin (Springer, Berlin, 1979) Vol. 31.

${ }^{2}$ M. Ritala, M. Leskela, L. Niinisto, T. Prohaska, G. Friedbacher and M. Grasserbauer, Thin Solid Films 250, 72 (1994).

${ }^{3}$ M. F. Al-Kuhaili, Opt. Mater. 27, 383 (2004).

${ }^{4}$ M. Lesser, Opt. Eng. 26, 911 (1987).

${ }^{5}$ M. Fadel, O. A. Azim, O. A. Omer, and R. R. Basily, Appl. Phys. A: Mater. Sci. Process. 66, 335 (1998).

${ }^{6}$ M. Zukic, D. G. Torr, J. F. Spann, M. R. Torr, Applied Optics 29, 4284 (1990).

${ }^{7}$ S. M. Edlou, A. Smajkiewicz, G. A. Al-Jumaily, Applied Optics 32, 5601 (1993).

${ }^{8}$ J. M. Khoshman, M. E. Kordesch, Surf. Coat. Technol. 201, 3530 (2006).

${ }^{9}$ J-W. Park, D-K. Lee, D. Lim, H. Lee and S-H. Choi, J. Appl. Phys. 104, 033521 (2008).

${ }^{10}$ M. T. Luque, E. S. Andres, A. d. Prado, I. Martil, M. L. Lucia and G. G. Diaz, J. Appl. Phys. 102, 044106 (2007).

${ }^{11}$ V. Pervak, F. Krausz and A. Apolonski, Thin Solid Films 515, 7984 (2007).

${ }^{12}$ S. V. Ushakov, A. Navrotsky, Y. Yang, S. Stemmer, K. Kukli, M. Ritala, M. A. Leskela, P. Fejes, A. Demkov, C. Wang, B.-Y. Nguyen, D. Triyoso and P. Tobin, Phys. Stat. Sol. (B) 241, 2268 (2004).

${ }^{13}$ Q. Fang, J.-Y. Zhang, Z. Wang, M. Modreanu, B. J. O’Sullivan, P. K. Hurley, T. L. Leedham, D. Hywel, M. A. Audier, C. Jimenez, J.-P. Senateur and I. W. Boyd, Thin Solid Films 453454, 203 (2004).

${ }^{14}$ H.C. Barshilia and K.S. Rajam, Surf. Coat. Technol. 201, 329 (2006). 
${ }^{15}$ H.C. Barshilia and K.S. Rajam, J. Mater. Res. 19, 3196 (2004).

${ }^{16}$ O.S. Heavens, Optical Properties of Thin Solid Films (Dover, New York, 1965).

${ }^{17}$ E.E. Chain, G. E. Carver and B.O. Seraphin, Thin Solid Films 72, 59 (1980).

${ }^{18}$ X. Luo, A.A. Demkov, D. Triyoso, P. Fejes, R. Gregory and S. Zollner, Phys. Rev. B 78, $245314(2008)$.

${ }^{19}$ Joint Committee on Powder Diffraction Standards, File No. 06-0318.

${ }^{20}$ Joint Committee on Powder Diffraction Standards, File No. 08-0342.

${ }^{21}$ X. Zhao and D. Vanderbilt, Phys. Rev. B, 65, 233106 (2002).

${ }^{22}$ H. Fujimori, M. Yashima, M. Kakihana and M. Yoshimura, J. Am. Ceram. Soc. 84, 663 (2001).

${ }^{23}$ E. Anastassakis, B. Papanicolaou and I. M. Asher, J. Phys. Chem. Solids 36, 667 (1975).

${ }^{24}$ G. He, M. Liu, L. Q. Zhu, M. Chang, Q. Fang and L. D. Zhang, Surf. Sci. 576, 67 (2005).

${ }^{25}$ S. Q. Wang, J. W. Mayer, J. Appl. Phys. 64, 4711 (1988).

${ }^{26}$ S. Ninomiya and S. Adachi, J. Appl. Phys. 78, 1183 (1995).

${ }^{27}$ S. Adachi, H. Mori, and S. Ozaki, Phys. Rev. B 66, 153201 (2002).

${ }^{28}$ D. Bhattacharyya and A. Biswas, J. Appl. Phys. 97, 053501 (2005).

${ }^{29}$ N.K. Sahoo, S. Thakur, M. Senthilkumar, D. Bhattacharyya, N.C. Das, Thin Solid Films 440, 155 (2003).

${ }^{30}$ A. Biswas, D. Bhattacharyya, H.C. Barshilia, N. Selvakumar and K.S. Rajam, Appl. Surf. Sci. 254, 1694 (2008).

${ }^{31}$ H. C. Barshilia, N. Selvakumar, K. S. Rajam and A. Biswas, J. Appl. Phys. 103, 023507 (2008).

${ }^{32}$ Y. He and J. Y. Feng, J. Cryst. Growth 263, 203 (2004). 
${ }^{33}$ C. A. Kennedy, M. A. White, A. P. Wilkinson and T. Varga, Phys. Rev. B. 75, 224302 (2007).

${ }^{34}$ R. Prakash, D. M. Phase, R. J. Choudhary and R. Kumar, J. Appl. Phys. 103, 043712 (2008).

${ }^{35}$ Z. Singh, S. Dash, R. Prasad and V. Venugopal, J. Alloys Compd. 244, 85 (1996).

${ }^{36}$ M. S. Samant, S. R. Bharadwaj, A. S. Kerkar and S. R. Dharwadkar, J. Nucl. Mater. 207, 98 (1993).

${ }^{37}$ K. Ajito, L. A. Nagahara, D. A. Tryk, K. Hashimoto and A. Fujishima, J. Phys. Chem. 99, $16383(1995)$. 
Fig. 1

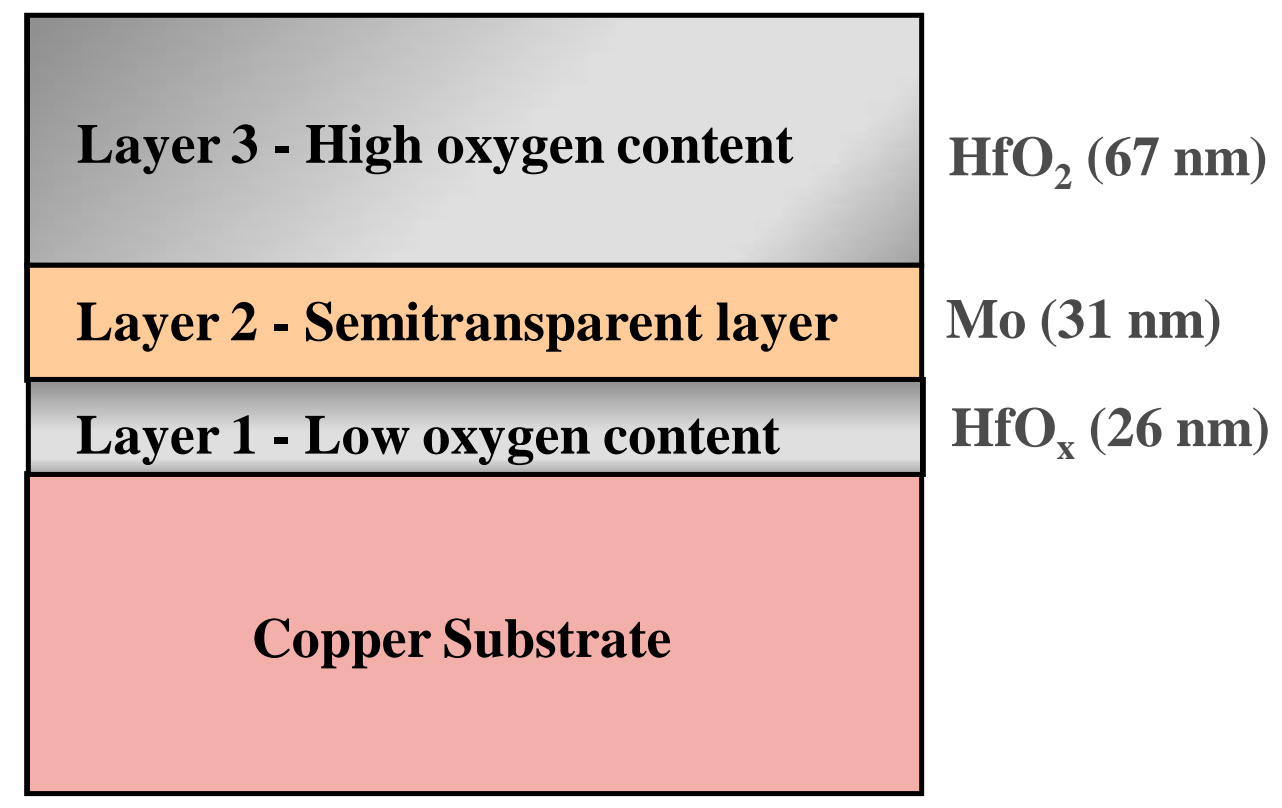




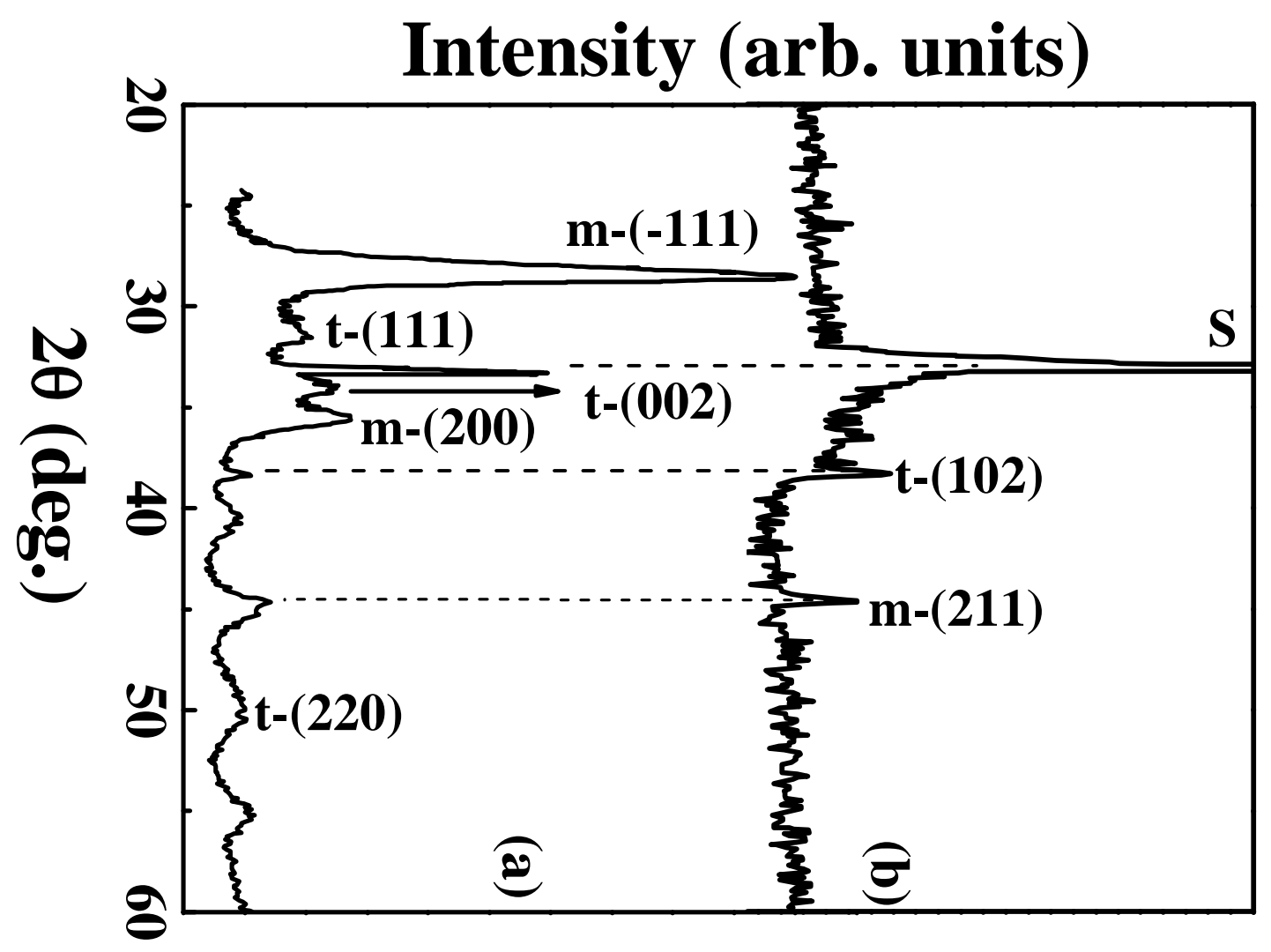


Fig. 3.

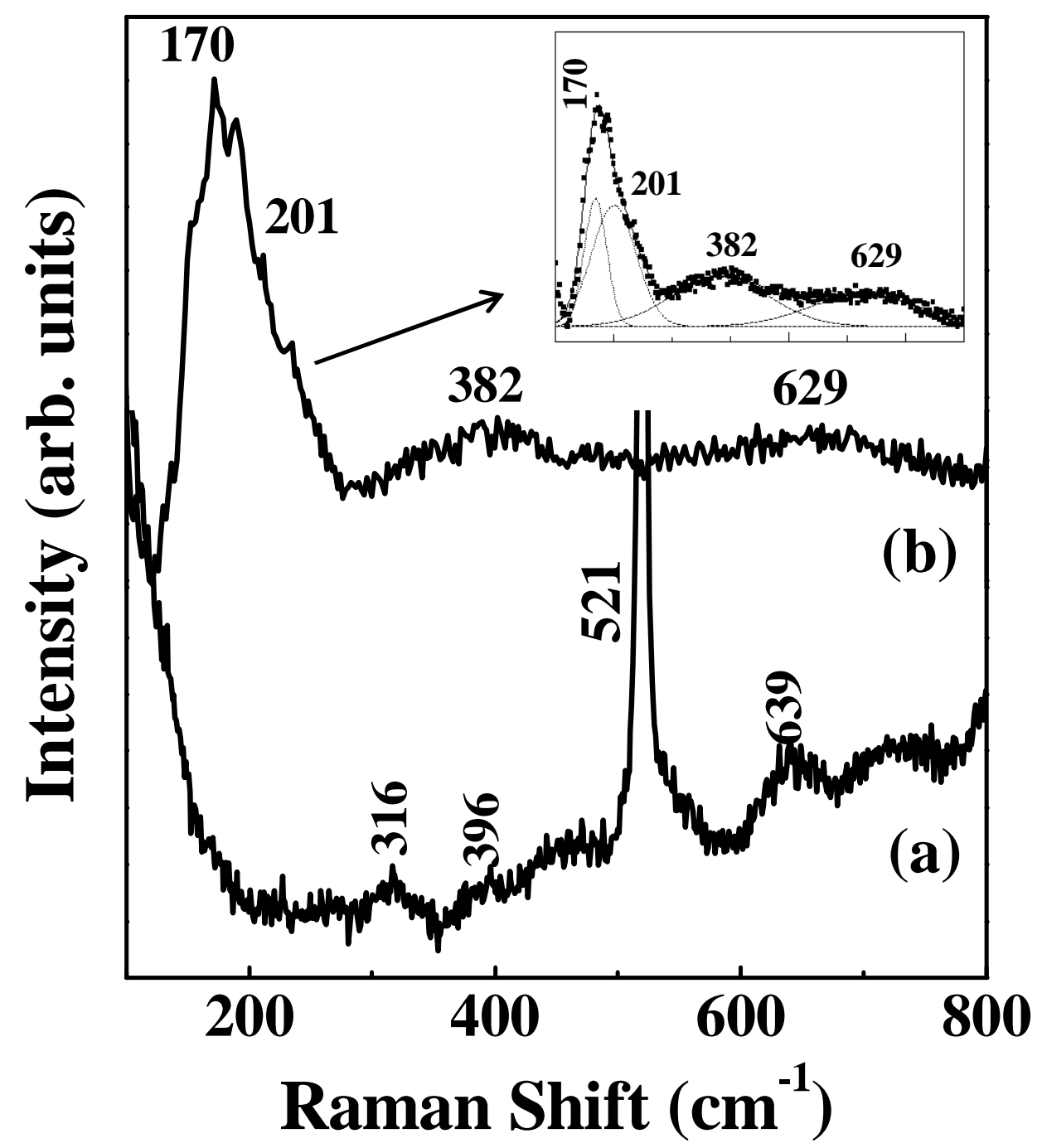


Fig. 4
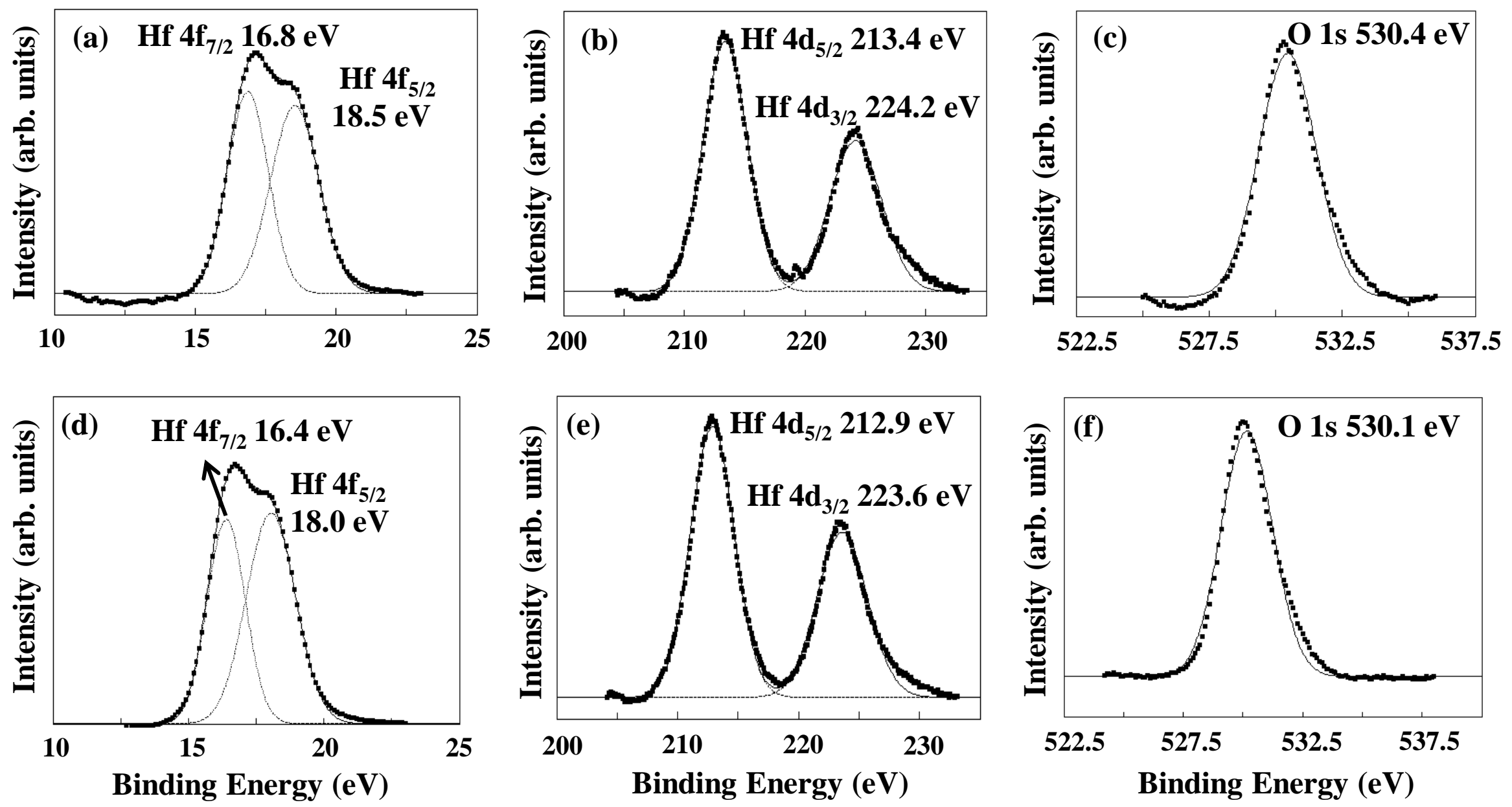
Fig. 5

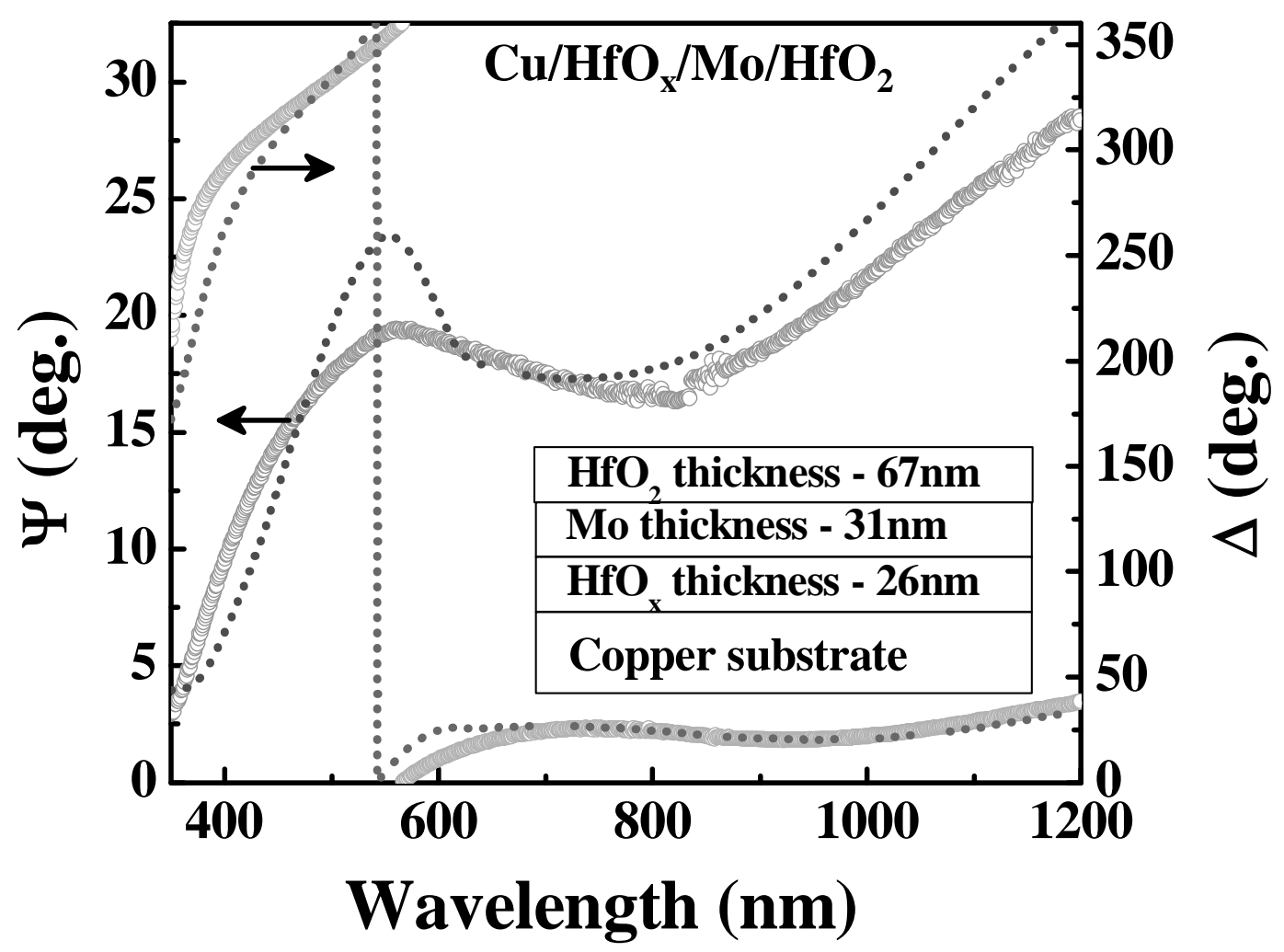


Fig. 6
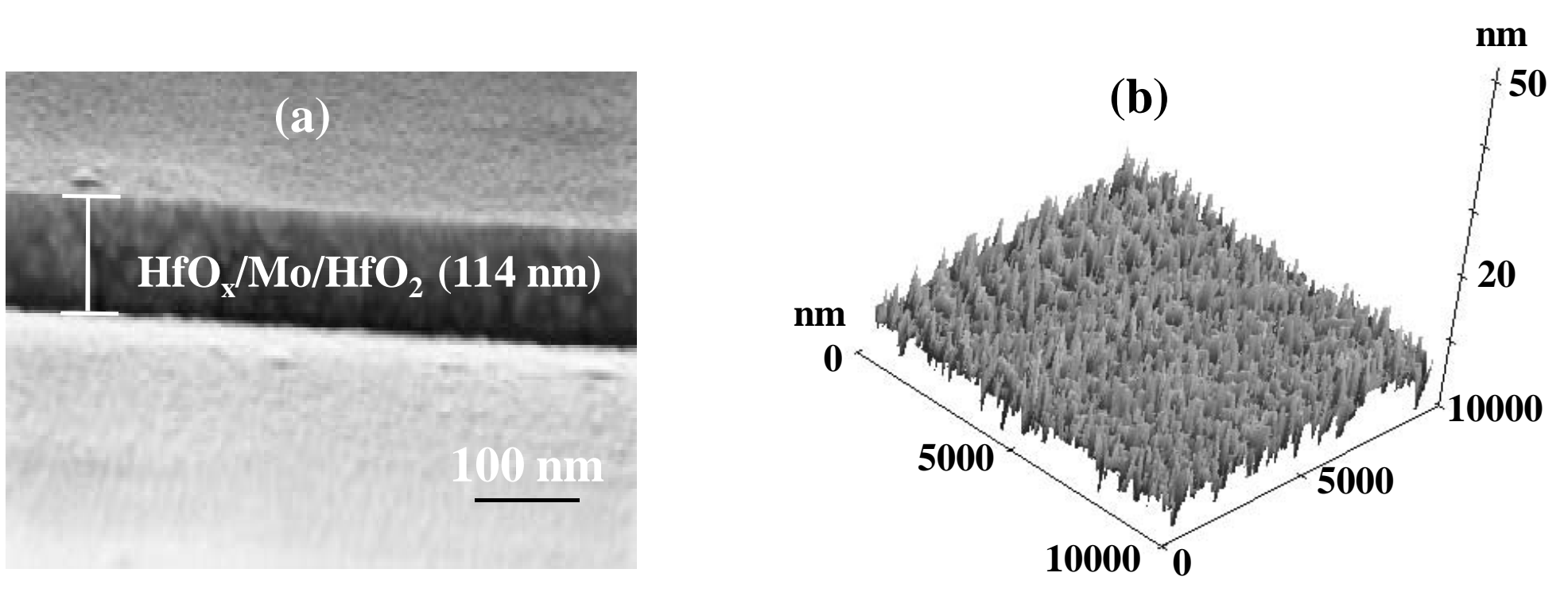
Fig. 7
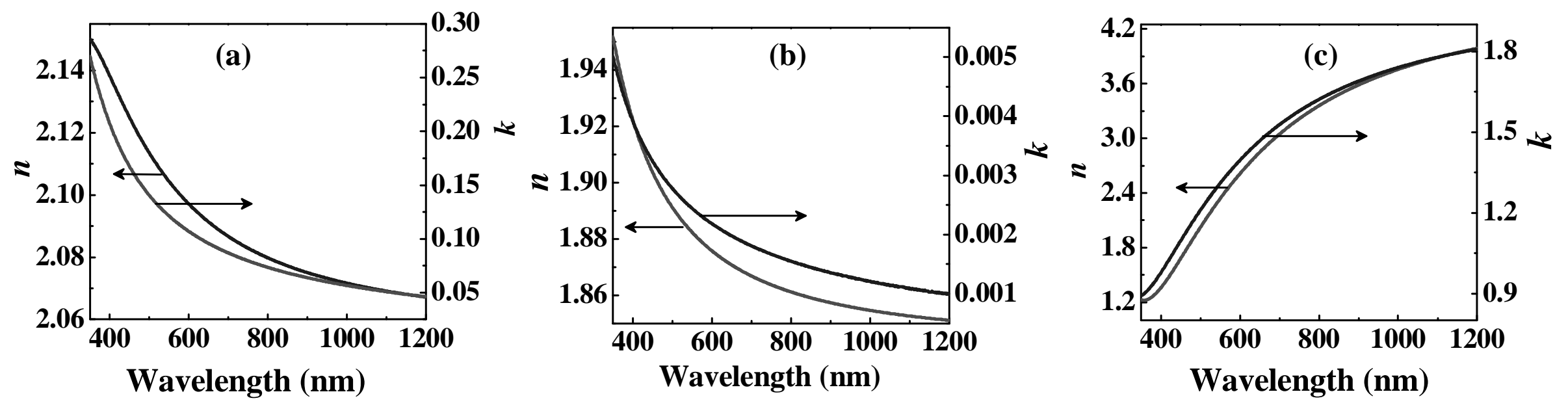
Fig. 8
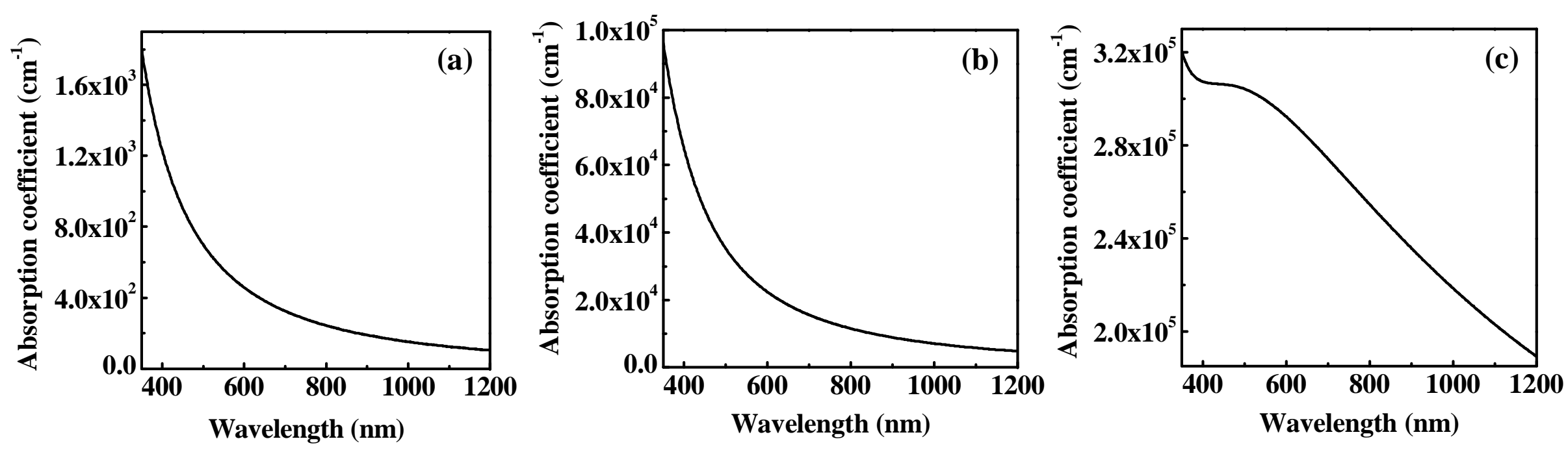
Fig. 9

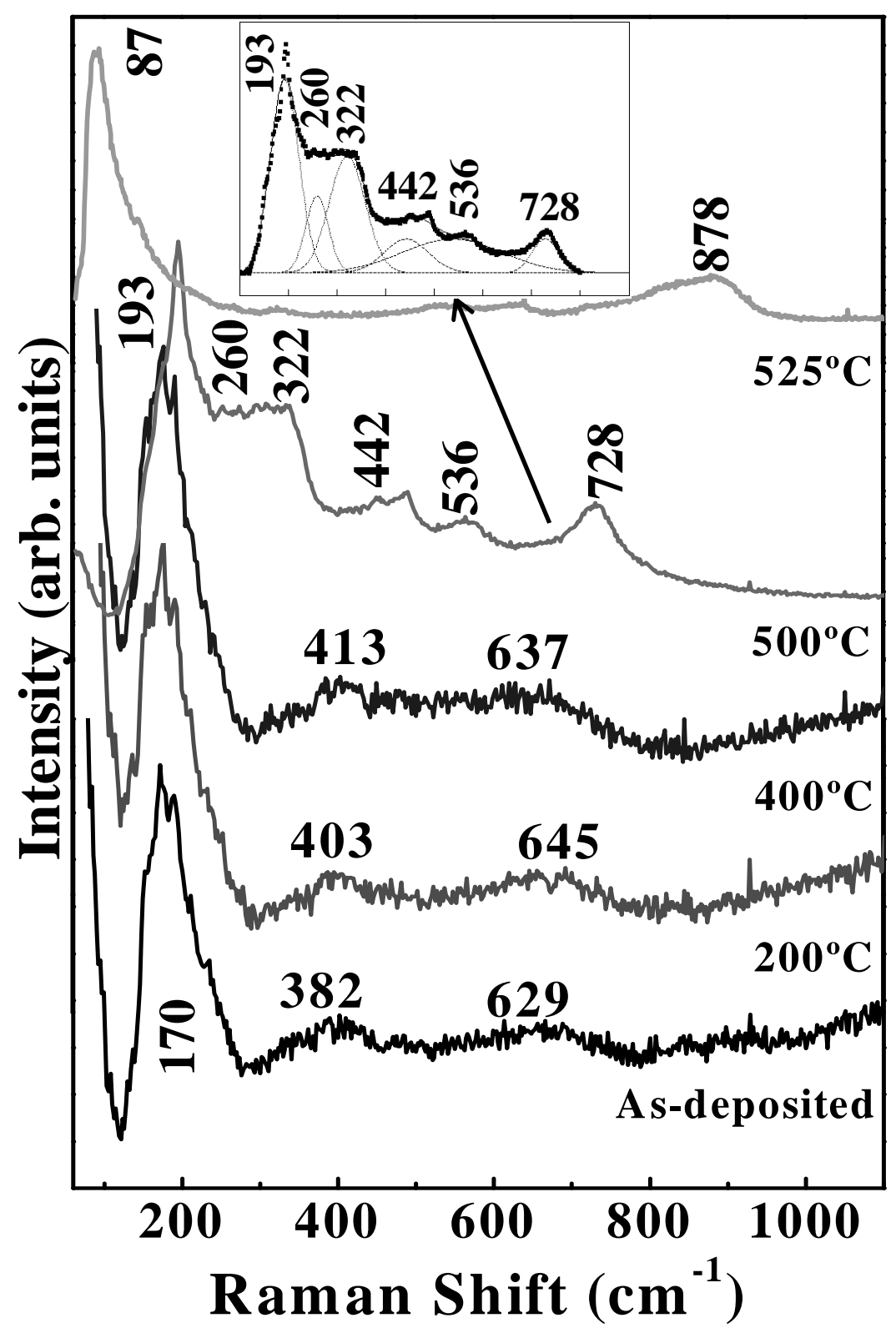




\section{Intensity (arb. units)}

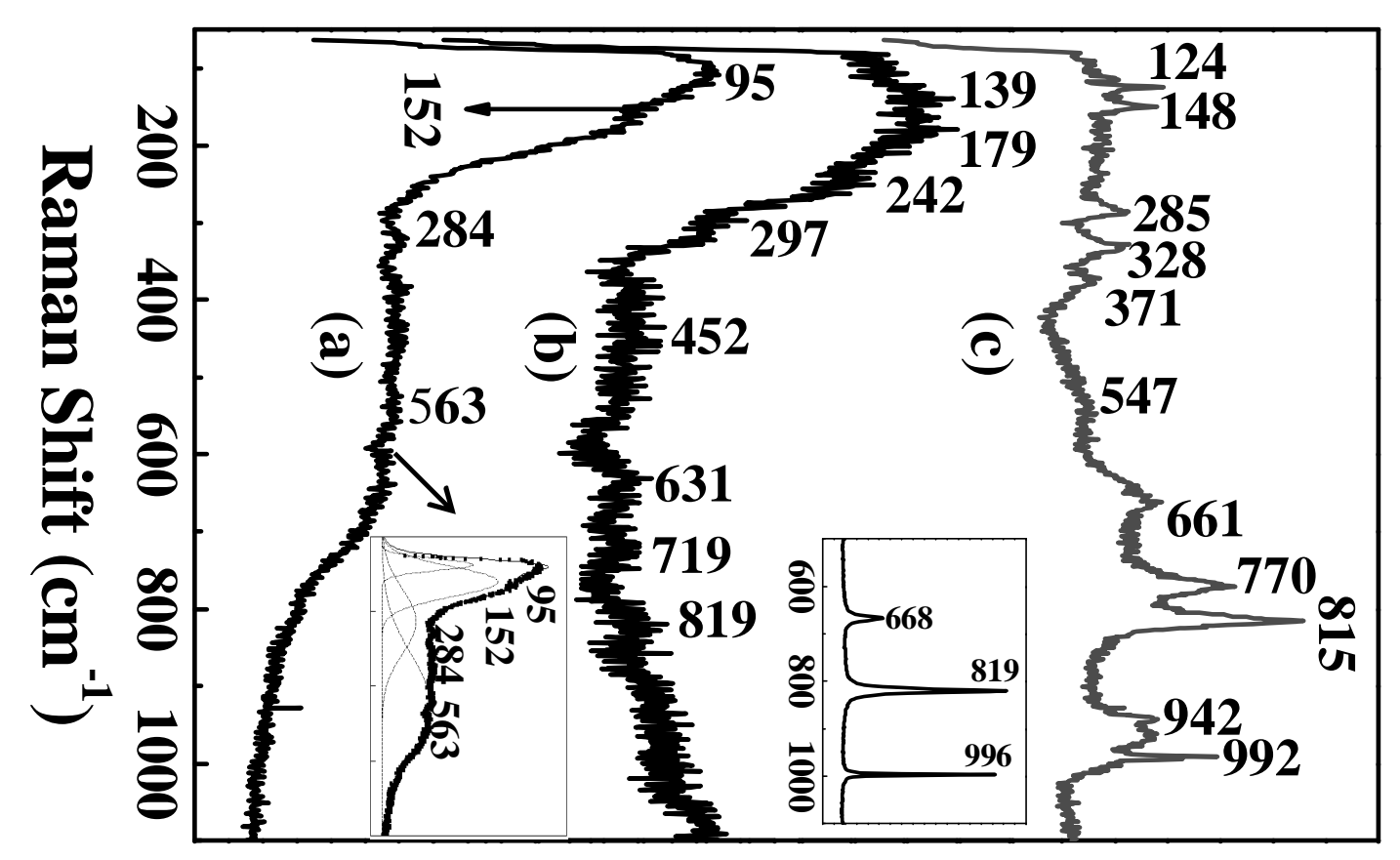


Fig. 11
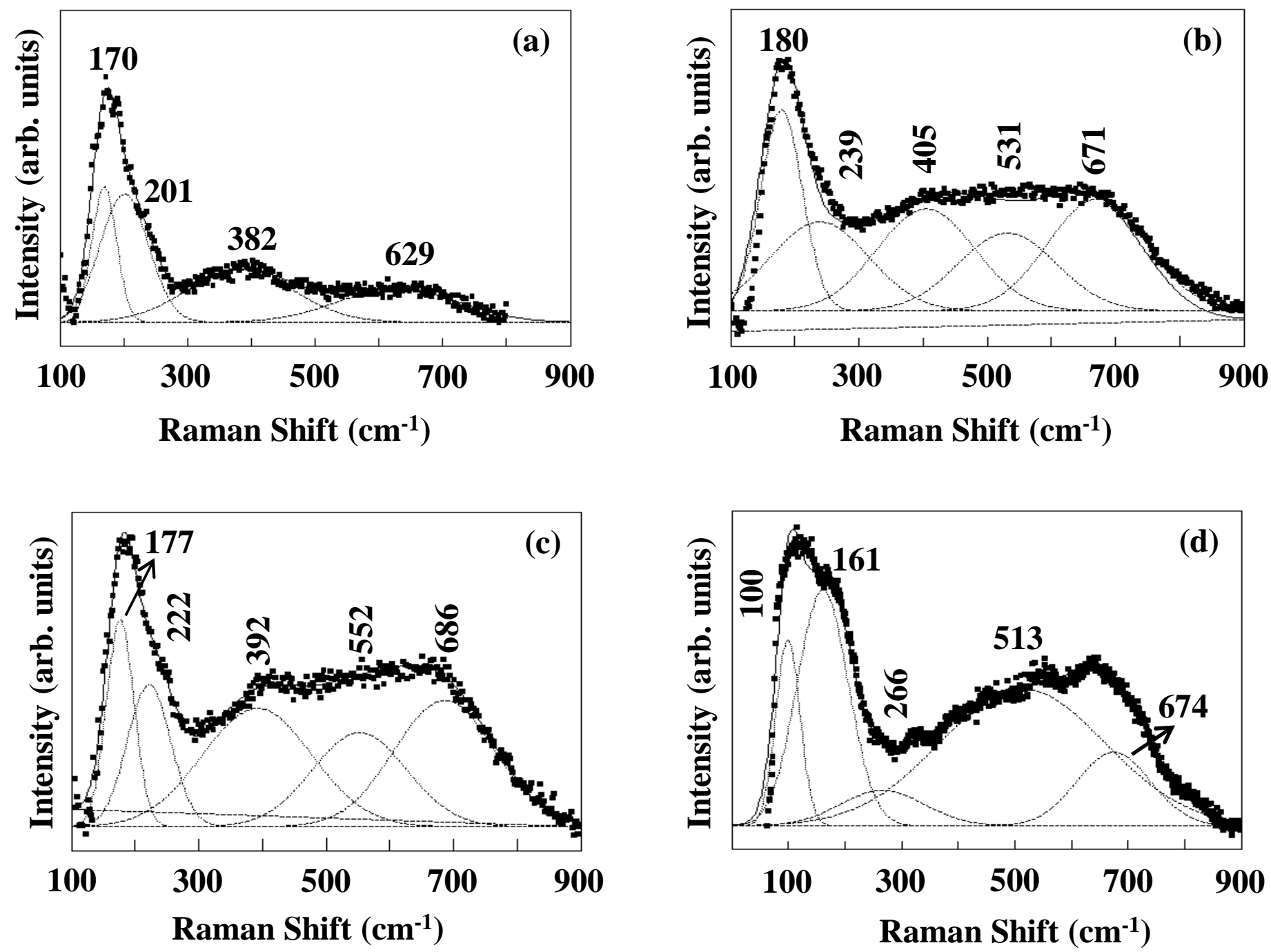